NBER WORKING PAPER SERIES

\title{
SOCIAL AND FINANCIAL INCENTIVES FOR OVERCOMING A COLLECTIVE ACTION PROBLEM
}

\author{
M. Mehrab Bakhtiar \\ Raymond Guiteras \\ James A. Levinsohn \\ Ahmed Mushfiq Mobarak \\ Working Paper 29294 \\ http://www.nber.org/papers/w29294 \\ NATIONAL BUREAU OF ECONOMIC RESEARCH \\ 1050 Massachusetts Avenue \\ Cambridge, MA 02138 \\ September 2021
}

We thank the Bill and Melinda Gates Foundation and the International Growth Center for financial support, Wateraid-Bangladesh, and Village Education and Research Committee (VERC), Bangladesh for their collaboration, and Mehrab Ali, Laura Feeney and Matthew Krupoff for excellent research assistance and field support. Zack Brown and seminar participants at AERE Summer Conference, 2017, the BMGF Monitoring, Evaluation and Dissemination for Scale (MEDS), 2017, Water and Health Conference at the University of North Carolina, 2018, and the ADBI-BMGF Webinar on Sanitation and Development provided helpful comments. All errors are our own. The views expressed herein are those of the authors and do not necessarily reflect the views of the National Bureau of Economic Research.

NBER working papers are circulated for discussion and comment purposes. They have not been peer-reviewed or been subject to the review by the NBER Board of Directors that accompanies official NBER publications.

(C) 2021 by M. Mehrab Bakhtiar, Raymond Guiteras, James A. Levinsohn, and Ahmed Mushfiq Mobarak. All rights reserved. Short sections of text, not to exceed two paragraphs, may be quoted without explicit permission provided that full credit, including () notice, is given to the source. 
Social and Financial Incentives for Overcoming a Collective Action Problem

M. Mehrab Bakhtiar, Raymond Guiteras, James A. Levinsohn, and Ahmed Mushfiq Mobarak NBER Working Paper No. 29294

September 2021

JEL No. O1,Q56

\begin{abstract}
$\underline{\text { ABSTRACT }}$
Addressing public health externalities often requires community-level collective action. Each person's sanitation behavior can affect the health of neighbors. We report on a cluster randomized controlled trial conducted with 19,000 households in rural Bangladesh where we randomized (1) either group financial incentives or a non-financial "social recognition" reward, and (2) asking each household to make either a private pledge or a public pledge to maintain hygienic latrines. The group financial reward has the strongest impact in the short term ( 3 months), inducing a 7.5-12.5 percentage point increase in hygienic latrine ownership. Getting people to publicly commit to maintaining and using a hygienic latrine in front of their neighbors induced a 4.2-6.1 percentage point increase in hygienic latrine ownership in the short term. In the medium term (15 months), the effect of the financial reward dissipates while the effect of the public commitment persists. Neither social recognition nor private commitments produce effects statistically distinguishable from zero.
\end{abstract}

M. Mehrab Bakhtiar

International Food Policy Research Institute

1201 I Street NW

Washington, DC 20005

m.bakhtiar@cgiar.org

Raymond Guiteras

Department of Agricultural and

Resource Economics

North Carolina State University

Raleigh, NC 27695

rpguiter@ncsu.edu
James A. Levinsohn

Yale School of Management

PO Box 208200

New Haven, CT 06520

and NBER

James.Levinsohn@yale.edu

Ahmed Mushfiq Mobarak

Yale School of Management

135 Prospect Street

Box 208200

New Haven, CT 06520

and NBER

ahmed.mobarak@yale.edu

A data appendix is available at http://www.nber.org/data-appendix/w29294

A pre-analysis plan for this paper is available at https://www.socialscienceregistry.org/trials/2227 


\section{Introduction}

Many inexpensive, efficacious technologies with the potential to address important development challenges are used at surprisingly low rates in developing countries (Foster and Rosenzweig 2010). Prominent examples include drinking water disinfectants (Ashraf et al. 2010), fertilizers (Duflo et al. 2011), nutritional supplements (Maluccio et al. 2009), high-yield crop varieties (Udry 2010), and rainfall insurance (Cole et al. 2014). The productivity and welfare benefits of many of these technologies are potentially very large, which makes low rates of adoption and use a central puzzle in development.

Social scientists and development practitioners have studied several explanations for low initial adoption: poor households may be liquidity or credit constrained (Dupas and Robinson 2013), they may simply not understand a technology's benefits (Foster and Rosenzweig 1995), they may be highly risk averse (Bryan et al. 2014), they may suffer from self-control problems (Banerjee and Mullainathan 2010), or learning externalities may lead to inefficient experimentation (Munshi 2003; BenYishay and Mobarak 2019). This paper tests strategies to promote a healthier technology based on another class of explanations: that adoption decisions may be inter-linked across households when there are public health externalities, and interactions with neighbors may mediate those decisions.

Sanitation is a leading example of this class of problem. Health gains from a household's use of a hygienic latrine likely accrue largely to other households in the community (Fuller et al. 2016; Andrés et al. 2017). One billion people, or about $15 \%$ of the world's population, currently practice open defecation (OD) in spite of the existence of simple, affordable pour flush latrines that effectively confine fecal matter in sealed pits (WHO and UNICEF 2017). Open defecation spreads bacterial, viral, and parasitic infections, including diarrhoea, polio, cholera and hookworm and has been identified as a leading cause of child stunting (Spears 2013; Chambers and Von Medeazza 2013; Augsburg and Rodríguez-Lesmes 2018) and infant 
death (Hathi et al. 2017). Diarrheal diseases kill nearly one million people per year (PrüssUstün et al. 2014), and cause nearly $20 \%$ of deaths of children under five in low income countries (Mara et al. 2010).

Research on barriers to sanitation adoption includes studies of interventions to educate and motivate communities (Pattanayak et al. 2009; Gertler et al. 2015), micro-finance loans to overcome credit constraints (BenYishay, Fraker, et al. 2017; Smets et al. 2021), and targeted subsidies to increase affordability and leverage social spillovers in adoption (Guiteras et al. 2015; Cameron et al. 2021). There has been much academic and policy interest in "community led total sanitation" (CLTS) interventions (Pickering et al. 2015), which aim to bring the community together to jointly discuss the public health externality problems. In this paper, we devise and test interventions that isolate specific aspects of the community-level interactions in CLTS programs.

Our intervention design also pays attention to the issue of proper use and maintenance after initial adoption. ${ }^{1}$ While adoption is necessary for health gains, it is not sufficient - hygienic latrines will only produce health benefits if they are consistently used and are kept in good condition so that fecal pathogens are safely isolated from the environment. This requires each household to incur time and materials costs to keep the latrine clean, conduct maintenance and dispose of waste properly.

The fact that the benefits largely accrue to others creates a divergence between the incidence of benefits and costs, and with it, a classic collective action problem - while it may be in all households' interests collectively to use and maintain hygienic latrines, any individual household may privately find it beneficial to deviate from the public optimum. When institutions are strong, regulation mandating adoption and enforcing use can solve this problem. However, in the absence of such institutions, other tools are required.

\footnotetext{
${ }^{1}$ See Coffey et al. (2014) on unused latrines in rural Northern India, Orgill-Meyer et al. (2019) and Pakhtigian et al. (2021) on long-term use patterns in Orissa, India, and Deutschmann et al. (2021) on pit-emptying in Dakar, Senegal.
} 
In this paper, we test several such tools designed to overcome this collective action problem. Our context is rural Tanore district in Bangladesh, where, in previous research, we evaluated a set of interventions intended to increase investment in hygienic latrines (Guiteras et al. 2015). In this study, we designed new interventions to help households overcome any collective action failures that may be impeding ongoing consistent use. As a basic, common treatment, we form groups of 15-20 neighboring households who participate in monthly meetings with a health worker from a well-known NGO to discuss sanitation, OD and disease risk. On top of this common treatment, we randomize four additional treatments. The first, "monetary reward," is a slight variation on the standard public finance policy prescription: a subsidy for a well-maintained hygienic latrine. The non-standard component is an element of joint liability: households receive the reward only if both that household's latrine is hygienic and a certain share of all households in the group maintain a hygienic latrine. While this payment for environmental service scheme is appealing, it may be challenging to sustain financially, and credible monitoring may be similarly difficult. Our second treatment, "recognition reward," attempts to address these shortcomings by substituting a non-pecuniary reward, a recognition certificate from the local government.

Our third treatment, "public commitment," explores whether a simple verbal coordination device can sustain a cooperative equilibrium (Schelling 1960). In public commitment groups, groups are asked to make a joint public (but non-binding) commitment in front of each other, stating that they will try to address the OD issue in their neighborhood by using and maintaining hygienic latrines. This public commitment could be operating through two mechanisms: the act of making a commitment, which as an "implementation intention" can itself spur action (Gollwitzer and Brandstätter 1997); and the fact that this commitment was made in public with others who are making the same public commitment. Our fourth treatment, "private commitment," was designed to separate these two mechanisms. In groups in the private commitment arm, households make the same pledge as those in the public commitment arm, but this pledge is made in private. 
These interventions are implemented at a large scale, covering a sample of 19,345 households in 107 villages, and we measure short-term (at the time of the assessment for rewards, roughly 3 months after the interventions began) and medium-term (12-15 months after assessment) effects. We find that group-level monetary reward has the strongest impact in the short term, inducing an 7.5 to 12.5 percentage point (pp) increase in the share of households with hygienic latrines. The public commitment treatment caused a 4.2 to $6.1 \mathrm{pp}$ increase in the same period. Neither the non-monetary reward nor the private commitment treatments had statistically significant impacts. In the medium term, the effect of the monetary reward dissipates, while the effect of the public commitment treatment persists. We find that in the case of both the monetary reward and public commitment treatments, households tended to meet the short-run assessment criteria for hygienic status through small, relatively inexpensive improvements to or repairs of existing latrines, rather than making large investments in major improvements or new latrines. In the public commitment group, households tended to maintain these small improvements into the medium-term, while those in the monetary reward group tended to let these improvements deteriorate.

The paper proceeds as follows: Section 2 describes the study setting and the sample; Section 3 describes our interventions and experimental design; Section 4 describes our data; Section 5 presents our estimation equations and results, with reduced-form treatment effects in Section 5.1 and mechanisms in Section 5.2; Section 6 concludes.

\section{Setting and Sample}

This study was conducted with 19,271 households in 107 villages in 4 unions (sub-districts) of Tanore district, Bangladesh. These villages were the site of a randomized evaluation of a set of interventions designed to study interdependencies in household investment in hygienic latrines (Guiteras et al. 2015). We refer to this first set of interventions as the "first set of 
interventions" or the "demand study interventions," and the second set, the focus of this paper, as the "second set of interventions" or the "incentives for use interventions." The study area was chosen in part because of its low level of latrine coverage: at baseline, $30.8 \%$ of households reported a regular level of open defecation among adults, 50.4\% reported that they had access to a hygienic latrine and $40.1 \%$ owned a hygienic latrine. This first set of interventions was conducted February 2012 - August 2012, with baseline data collected December 2011 - February 2012 and four rounds of followup data collected through May 2013 - July 2013. Guiteras et al. (2015) show that subsidies increase adoption of hygienic latrines, both directly - among households winning a subsidy voucher in a public lottery -

and indirectly - the share of subsidy winners was randomized at the community level, and as this "saturation" increased, investment increased among both subsidized and unsubsidized households. The current study was intended to understand how to sustain or increase these gains.

In our 107 study villages, we created 1,236 groups of approximately 14-17 neighboring households, roughly 4-16 groups per village, and the incentives-for-use interventions were conducted at this group level. While the unit of intervention was the group, randomization was at the village level.

\section{Interventions and Experimental Design}

In this section, we describe the treatments and the randomization. A timeline for a typical village is provided in Figure 1. 


\subsection{Common Intervention}

All 980 treatment groups (in 84 treatment villages) received a basic intervention consisting of monthly meetings for three consecutive months with a Health Motivator to encourage investment in and maintenance and use of hygienic latrines. ${ }^{2}$ Health Motivators, trained by and contracted from our implementation partner VERC, discussed the health risks of open defecation and unhygienic sanitation practices, the collective nature of the problem (i.e., the externality in non-technical terms), the types and costs of hygienic latrines, and the current level and monthly change in the share of households with or advancing towards a hygienic latrine. The intervention protocol is provided in Section SM3 of the Supplementary Materials.

In the common as well as in the cross-cutting interventions, the Health Motivator provided both a general, conceptual definition of a hygienic latrine and a specific, technical definition. The conceptual definition emphasized that a hygienic latrine was one that:

1. Limits the spread of diseases caused by feces in the water and keeps the environment pollution free;

2. Confines feces in an enclosed pit so that they cannot be seen or smelled;

3. Prevents flies or other insects from entering the pit.

The specific, technical definition listed the characteristics based on which a latrine was judged to be hygienic, in particular:

1. There must be a slab and it cannot be broken.

\footnotetext{
${ }^{2}$ Different sources define "hygienic" in different ways, and there are also other labels such as "improved" or "sanitary." Conceptually, a hygienic latrine safely confines feces. For pour-flush latrines (the relevant type in our context), this typically requires a water seal to block flies and other insects, and a sealed pit to store fecal matter for safe disposal (Hanchett et al. 2011). In our survey data, we define an unimproved latrine as a bucket, a simple pit with no slab or cover, or a "hanging latrine" (a platform over open land or water), and a hygienic latrine as having a functional, non-broken slab and water seal leading to a sealed pit.
} 
2. There must be a water-seal (locally known as 'gooseneck' or 'siphon') and it cannot be broken.

3. Different latrine components such as rings, delivery pipe, Y-junction (whenever applicable), pit cover (whenever applicable), etc. should be functional and without any leaks.

4. There should not be any feces in or around the latrine.

5. The latrine cannot pollute the environment. In particular, the latrine/delivery pipe can only discharge the waste into a sealed pit and not to the external environment (for example, a stream or just out in the open).

These characteristics of a hygienic latrine were relayed to participants at each of the three group meetings. ${ }^{3}$ Participants were made aware of the fact that for latrines to be considered hygienic all the above mentioned requirements had to be met by the specified deadline, approximately four months after the intervention began.

Health Motivators also emphasized that a latrine's hygienic status was not just determined by the collection of parts, but depended on maintenance, repair and sanitary use. Discussions, both with the group and with individual households, emphasized small improvements or repairs that could be made to achieve hygienic status, and how to maintain hygienic status once it was achieved.

\footnotetext{
${ }^{3}$ Households were also encouraged to ensure that no gaps existed between different latrines components that could compromise the 'sealed' nature of a pit. For single-pit latrines, this meant that there would not be any gap between the cover of the slab and the top-most ring. For offset latrines (involving multiple pits or a pit that is not situated directly below the latrine) there should not be any gap between the top-most ring and the pit cover. Moreover, although not perfectly observed (and therefore, not a strict requirement of a hygienic latrine) households were encouraged to install adequate number of rings depending on the depth of the latrine pit.
} 


\subsection{Reward Treatments}

There were two reward treatments, monetary and non-monetary, both of which were conditioned on both the household's own status and the share of households in the group achieving hygienic latrine status. This element of "joint liability" was intended to incentivize households to motivate and assist each other.

The monetary reward consisted of a cash payment to the household if, at the end of the intervention period, (a) the household owned a hygienic latrine and (b) the share of households in that group with a hygienic latrine was above a designated threshold. Hygienic was defined as described in Section 3.1 above. The reward was BDT 250 (USD 3.33) in groups that surpassed the lower of the two thresholds and BDT 500 (USD 6.67) in groups that surpassed the higher of the two thresholds. ${ }^{4}$ For comparison, the cost of building a single-pit hygienic latrine was approximately BDT 2350 (USD 31.33), while common improvements to existing latrines that would be necessary to reach hygienic status cost substantially less, e.g., a new water seal BDT 65 (USD 0.87), delivery pipe BDT 360 (USD 4.8).

The non-monetary reward consisted of a certificate of hygiene attainment from the local government, presented to qualifying households in a public ceremony. ${ }^{5}$ The non-monetary reward used the same standard for "hygienic" as the monetary reward.

Thresholds were determined based on baseline hygienic latrine ownership by union. In three of the four unions, the lower threshold was set at one-third of households and the upper threshold at two-thirds. In one union with significantly lower hygienic latrine ownership at baseline, the lower and upper threshold were set at one-quarter and one-half, respectively. A lower threshold was set such that even low baseline-ownership groups would feel they could attain something, while high baseline-ownership groups would have something to reach for.

\footnotetext{
${ }^{4}$ US dollar equivalents at $75 \mathrm{BDT} / \mathrm{USD}$, the approximate market exchange rate at the time.

${ }^{5}$ This certificate was printed on thick glossy paper, so it could be displayed on an interior wall. However, no weatherproof frame was provided. As a result, it would be difficult for a household to display the certificate outdoors where it would be publicly visible.
} 
We also chose thresholds that were simple and easy to explain at a group meeting: a phrase like "two out of every three households" is easier to understand than a phrase like "sixty-six percent of all households."

The assessment was conducted approximately four months after the intervention began, after three group meetings with the Health Motivator. Health Motivators did not conduct assessments in villages where they had worked. See Section 4.3 for a discussion of the

assessment process. The full survey instrument is provided in Section SM4 of the Supplementary Materials. Households knew the deadline for achieving hygienic status, and that the assessment would occur within one-two weeks after the deadline, but did not know the specific day of the assessment.

\subsection{Commitment Treatments}

There were two commitment treatments, public and private.

In the public commitment arm, during each group meeting, members from all the households of a group were encouraged to make a public pledge that those who did not yet have hygienic latrines would meet hygienic latrine standards as set by the project. Those with hygienic latrines pledged to help others reach the goal within the time limit set by the project. The script of the pledge, in English translation, was: "I hereby promise before everyone present that I will do my best to set up hygienic latrines or improve existing ones into hygienic latrines for myself and for my neighbors by [end date]." In the public commitment arm, this pledge was repeated at the end of each monthly group meeting.

In the private commitment arm, health motivators visited each household in the group after each group meeting. The member of the household attending the meeting would be encouraged by the Health Motivator to make a commitment before the health motivator that 
he/she would transform their unhygienic latrines to hygienic ones within the time limit set by the project. The script of the pledge was identical to that in the public commitment arm.

\subsection{Experimental Design}

The reward and commitment treatments lead to a 3x3 design, plus a pure control group. The design is summarized in Table 1. Although the treatments were implemented at the group level, randomization was conducted at the village level because of the potential for spillovers within village. We allocated approximately $25 \%$ of villages to pure control, and then the remaining villages were intended to be allocated equally across the commitment and reward treatments. With 107 villages (84 treatment villages), we did not expect to have adequate power to detect interaction effects. The randomization was stratified by union. The resulting assignment is presented in Table 1. Because of a coding error, there is some imbalance in the number of villages per cell. Most significantly, the basic treatment only cell was under-populated ( 8 villages), so we will use Wild bootstrap standard errors for inference in our group-level analyses (MacKinnon and Webb 2017; Roodman et al. 2019). Descriptive statistics and balancing tests for key baseline observables are provided in Table 2 .

\section{Data}

The full timeline of all data-collection activities for a typical village is presented in Figure 1.

\subsection{Previous Surveys}

As noted above, several rounds of surveys had been conducted for the previous demand study. Specifically, these were: a census, a baseline (conducted on a $50 \%$ subsample, stratified by 
village) and four monitoring rounds focused on latrine improvements and condition. In this study, we primarily use: the census data on landless status, social networks, in particular who households identify as local leaders; the third followup monitoring round, in which we collected location data to assist in creating groups and to construct density measures.

\subsection{Baseline Latrine Coverage}

A few months before beginning the interventions in this study, we conducted what we will refer to as the "baseline" survey for this study. ${ }^{6}$ We collected data from all households on latrine ownership, including detailed information on the condition of each household's latrine. This allowed us to classify each household's latrine as "none," "non-hygienic," or "hygienic." We include hanging latrines (an exposed platform over a marsh or stream) and uncovered pits in the "none" category, since these are effectively the same as open defecation in terms of disease, and cannot possibly be transformed into a hygienic latrine through simple improvements. This provided our baseline measures of our outcome variables. We used these data to determine union-specific thresholds for the reward treatments when designing the interventions.

\subsection{Short-term Outcomes}

At the end of the intervention, we collected data on latrine investment, use and maintenance. In reward and recognition groups, these data were collected as part of the reward determination process. These data were collected 1-2 weeks after the program's end date; households knew the general time frame but not the specific date. For budgetary reasons and because Health Motivators already had the training to assess latrine conditions, we used Health Motivators

\footnotetext{
${ }^{6}$ This was the fourth round of followup data-collection for the project as a whole. We will refer to the baseline survey for the overall project as the "demand study baseline." See Figure 1 for the full project timeline.
} 
to collect these data, but no Health Motivator collected data in a village where he or she had led an intervention. The Health Motivators that collected data were not informed of the village's treatment status, nor which Health Motivators had led the intervention in that village. Similarly, Health Motivators were not told which of their peers had collected the evaluation data in villages where they had led the intervention. In addition, to understand the mechanisms for the success or failure of the intervention, households were asked whether they received any assistance (financial, labor, advice) from community members, and whether they were pressured or encouraged by others in their group.

The criteria by which a household's latrine was judged "hygienic" for the purpose of the reward are given in Section 3.2. See the Supplementary Materials for precise definitions for coding the outcome variables of interest (Section SM1) and the survey instrument (Section SM4). Data were collected following the same protocol in all villages, regardless of treatment status.

\subsection{Medium-term Outcomes}

Medium-term outcome data were collected 12-15 months after the assessment (June 2015 - August 2015). This round served as an endline survey for the project as a whole, and so included several lengthy socio-economic and demographic modules. Because of budget constraints, we conducted this survey with the $50 \%$ subsample surveyed at baseline in the demand study (see Sec. 4.1 above). The baseline subsampling was stratified by village, and since the sub-village groups for this study had not been created yet, our endline subsample was unbalanced across groups. To avoid under-sampling groups, we identified any groups with fewer than six households included in the endline sample, determined how many households would be needed to have endline data for six households in the group, and randomly sampled that many additional households in the group. With this "top-up" sample, we conducted a 
brief endline survey on latrine status only, using the same modules on latrine status, use and maintenance as with those households receiving the full endline survey.

\section{$5 \quad$ Estimation and Results}

\subsection{Program Effects}

To measure reduced-form effects of our treatments, we estimate

$$
\begin{aligned}
y_{g v} & =\beta_{0}+\beta_{1} \text { Incent }_{v}+\beta_{2} \text { Cert }_{v}+\beta_{3} \operatorname{Priv}_{v}+\beta_{4} \operatorname{Publ}_{v} \\
& +\delta y_{0 g v}+\gamma \text { ShareLandless }_{g v}+\varphi_{u}+\varepsilon_{g v}
\end{aligned}
$$

where $y_{g v}$ is the outcome variable of interest (e.g., share of households owning a hygienic latrine) for group $g$ in village $v$, Incent $v$ and Cert $_{v}$ are indicators for village $v$ 's reward treatment assignment (financial incentive and social incentive, respectively), $\mathrm{Priv}_{v}$ and $\mathrm{Publ}_{v}$ are indicators for village $v$ 's commitment treatment assignment (private commitment and public commitment, respectively), $y_{0 g v}$ is the pre-intervention level of the outcome variable (McKenzie 2012), ShareLandless $g_{v}$ is the share of landless households in the group, which proxies for the financial resources available to the group as a whole, $\varphi_{u}$ is a set of union fixed effects, and $\varepsilon_{g v}$ is an error term which may be correlated at the village level (the level of randomization).

The coefficients $\beta_{1}$ and $\beta_{2}$ represent the effects of the reward treatments, controlling for potential imbalances in the commitment treatment, while coefficients $\beta_{3}$ and $\beta_{4}$ represent the effects of the commitment treatment, controlling for potential imbalances in the reward treatment. $^{7}$ These effects are conditional on receiving the common messaging treatment,

\footnotetext{
${ }^{7}$ As discussed in Muralidharan et al. (2020), in a factorial (interacted) design, the interpretation of coefficients in this "short" regression depends on priors about interaction effects. In the presence of interactions
} 
and we do not include pure control villages. That is, the omitted category in our main specifications consists of villages receiving the common messaging treatment, but no other treatment (cell A in Table 1), and our estimates should be interpreted as effects relative to this basic, common treatment. ${ }^{8}$

Our main outcome of interest is the share of households in the group household owning a hygienic latrine. As discussed in Sections 3.1 and 4, "hygienic" refers not just to the physical components (especially, water seal and sealed pit), but also the condition of these components (e.g., no leaks). Ideally, we would like to estimate effects on actual use and open defecation but these are difficult to measure objectively. Households may overstate the condition of their latrine and understate their rate of open defecation because of social desirability bias, and this is especially likely when a reward or their reputation may be at stake. In contrast, whether a household owns a hygienic latrine and whether that latrine is being kept clean can be assessed in a fairly objective manner. Our evaluation visits were unannounced so households could not meet our criteria by rushing to complete a repair or a major cleaning, although we cannot rule out that news of the assessment team's arrival in the village would spread in time to allow a household to conduct some minor cleaning.

\section{Short-term results}

Table 3 reports the short-term effects of the different treatment arms. We estimate equation (1) without controls in column 1, then add union fixed effects, the baseline value of the outcome variable, and the share of households in the group that are landless in columns 2 , 3 and 4, respectively. The last of these is our pre-specified preferred model. The unit of between treatments, Incent ${ }_{v}$, for example, should be interpreted as the average effect of the incentive treatment in a context where some groups are receiving no other treatment, some the public commitment treatment, and some the private commitment treatment. When we estimate fully interacted factorial models, we see little evidence of interaction effects (see Figures B1 and B2), but as Muralidharan et al. (2020) point out, these tests have low power. In retrospect, it would have been preferable to design the experiment without treatment interactions.

${ }^{8}$ This basic treatment had no effect on our main outcomes when compared to pure control, see Appendix A 
observation is the group, and groups are weighted by the number of households in the group, although results are not sensitive to weighting (see Appendix Table B1). We report standard errors robust to clustering at the village level (the level of randomization) in parentheses. Additionally, in brackets we report $95 \%$ confidence intervals from wild cluster bootstrapping for our coefficients of interest (MacKinnon and Webb 2017; Roodman et al. 2019). Estimated coefficients from column 4, with 95\% confidence intervals, are plotted in Figure 2.

As shown in Table 3, the monetary reward treatment is most effective at increasing hygienic latrine ownership in the short term. The point estimate ranges from +7.5 to +12.5 percentage points (pp) depending on the specification, relative to an omitted category mean of $45.1 \%$. The public commitment treatment increases ownership by 4.2 to $6.1 \mathrm{pp}$. The effects of the reward certificate and the private commitment are both economically small and statistically insignificant.

It is possible that the impact of these interventions on the overall health environment could be greater than just the effect on ownership if households allow others to use their hygienic latrine. However, when we use access to a hygienic latrine as the outcome variable rather than ownership, we see little evidence of this (see Appendix Table B2). In Appendix Table B3, we see that households appear to pay attention to the specific requirement built into our intervention: unlike hygienic latrine ownership, 'any latrine ownership' (including non-hygienic) does not respond at all.

We prioritize our direct observation of the latrine condition as our preferred outcome rather than self-reported open defecation, because data on these short-term outcomes were collected as part of the end-of-intervention assessment and therefore even more prone to bias than usual.We see little impact on self-reported open defecation, as shown in Appendix Table B4. This implies that the successful interventions appear to be inducing households already using latrines to continue to do so while upgrading their existing latrines, rather than persuading open defecators to build new latrines or use existing latrines. 


\section{Medium-term results}

To measure effects in the medium-term, we again estimate equation (1) using endline ownership (12-15 months after the intervention) as the outcome variable. The results are reported in Table 4, with estimated coefficients and 95\% confidence intervals from the pre-specified preferred specification (column (4) in the table) plotted in Figure 3. The effect of the monetary reward has faded $(+1.0$ to $+5.2 \mathrm{pp}, p<0.1$ in only one of four specifications $)$, while the effect of the public commitment treatment persists $(+6.1$ to $+7.6 \mathrm{pp}, p<0.05$ in all specifications). As in the short term, neither the reward certificate nor the private commitment have statistically significant effects. Again, these results are not sensitive to weighting (see Appendix Table B5).

There may be some enhancement of the effect of the public commitment treatment on the community environment beyond ownership, as its effect on access is slightly greater (8-9 percentage points increase in access; see Appendix Table B6). While this is plausible given that the public commitment treatment placed greater emphasis on collective responsibility than the other treatments, we consider this only suggestive, since the marginal gain in 'access' over 'ownership' is only an extra 1-2 pp. As with the short-term results, the effects are concentrated on 'hygienic latrines' (the target of our intervention design), not 'any latrine' (see Appendix Table B7). Similarly, the effects of the interventions on household self-reported open defecation remain small (Appendix Table B8). ${ }^{9}$

\footnotetext{
${ }^{9}$ For comparability with the short-term followup, we also report results using open defecation as inferred from the surveyor's assessment. Again, we find no effect, see Appendix Table B9.
} 


\subsection{Mechanisms}

\section{Household investments and behavior}

The clear pattern that emerges is that monetary rewards produce the largest short-term gains in hygienic latrine ownership which dissipates, while the public commitment treatment produces a steady increase which persists for at least a year or more. In this section, we delve into our detailed data on latrine components to understand the specific investment decisions households made under different treatments that could produce these patterns. The effects we show in Tables 3 and 4 could have been produced by either households investing in entirely new hygienic latrines, or making smaller investments to maintain or improve their existing latrines. We directly asked all households these questions - and find no significant effect of any treatment on "construction of a new latrine since Nov 1, 2013" (which is the start of our intervention period). In contrast, we find significant effects on "purchased/installed specific latrine components since Nov 1, 2013".

In Tables 5 and 6 , we investigate the specific latrine components the households prioritized for investment. We show effects on the three most important components that - when properly installed, functional and unbroken - define a latrine to be hygienic. These components are a concrete slab (on which the ceramic pan is placed, where the user squats), a water seal (to prevent bad smells and flies from moving in and out of the pit where the waste is stored), and the cover for the latrine pit and rings that safely confines the accumulated waste and prevents any leakages. We see statistically significant investments in all three components in the short-run under the monetary reward treatment, but this dissipates in the medium term. In contrast, we observe a significant $4.9 \mathrm{pp}$ increase in functional, intact pit cover and rings in the medium term under the public commitment treatment. One characteristic that distinguishes the pit cover from the other components is that it sits outside the toilet and its privacy shield (since the pits have to be emptied periodically, and are designed to be 'offset' 
from the toilet and not directly underneath), and therefore more easily visible to neighbors. Under the 'public commitment' treatment, we detect investments in the component that neighbors can more easily monitor.

Some analogous patterns emerge in Tables 7 and 8, where we examine outcomes related to latrine maintenance. We orient all variables so that one corresponds to better condition and zero to worse. We assign one to households that own a latrine with the specified desirable characteristic, and zero to households that either own a latrine without the desired characteristic or do not own a latrine. The proxies analyzed are no bad smell noticed, no leaks observed, and whether water and soap for hand-washing are present at or near the latrine. Again, there are improvements in all dimensions in the short-run under the monetary reward treatment, which dissipate after a year. In contrast, there are statistically significant effects on avoiding bad smells and leaks in the medium terms under the public commitment treatment.

Again, smells and pit leaks are the most visible components of maintenance, as opposed to water, soap and flies inside the toilet, which are aspects that neighbors cannot easily monitor. Avoiding leaks and smells requires the household to invest in fixing broken pit covers and rings, which are precisely the components we observed statistically significant improvements in Table 6. In summary, the data are consistent with the households who were asked to make a public commitment to maintain and use hygienic latrines making the investments in both latrine components and maintenance that avoid the most obvious, visible failures that can create slippage into a 'non-hygienic' sanitation territory.

In Table 9, we study the nature of interactions between households within the same treatment group, to investigate whether the interventions generated any conversations, cooperation, advice, or reciprocity that ultimately produced the changes in investment behavior. We show effects of the treatments on indicators for whether the household reports receiving different types of assistance or information from their neighbors, or pressure from others in the group. 
Generally speaking, all treatments led to greater assistance, advice and information sharing, so our interventions were successful in achieving the immediate, proximate goal. But we don't observe any clear pattern that helps explain why those conversations and assistance converted into persistent hygienic latrine maintenance effects in the 'public commitment' treatment.

\section{Household Characteristics}

To examine the extent to which program effects vary with respect to household characteristics, we modify equation (1) in two ways: by using household-level data and by interacting household characteristics with treatments. Specifically, we estimate

$$
\begin{aligned}
y_{h g v} & =\alpha_{0}+\alpha_{1} D_{h g v} \\
& +\sum_{p=1}^{4} \beta_{p} \cdot 1\left\{\text { Treat }_{v}=p\right\}+\sum_{p=1}^{4} \theta_{p} \cdot 1\left\{\text { Treat }_{v}=p\right\} \times D_{h g v} \\
& +\delta y_{0 g v}+\gamma \text { ShareLandless }_{g v}+\varphi_{u}+\varepsilon_{h g v}
\end{aligned}
$$

where $y_{h g v}$ is the outcome variable of interest for household $h$ in group $g$ in village $v, D_{h g v}$ is a characteristic of household $h, 1\left\{\right.$ Treat $\left._{v}=p\right\}$ is an indicator for the treatment status of village $v$, i.e., $p=1,2,3,4$ refer to financial incentive, social incentive, private commitment and public commitment, respectively, and all other variables are as defined in equation (1). The coefficient $\alpha_{1}$ represents the level effect of characteristic $D$, i.e., the association of $D$ with the outcome variable $y_{g v}$ in the comparison group, the coefficient $\beta_{p}$ represents the level effect of treatment $p$, i.e., the effect of treatment $p$ on households with $D=0$, and the coefficient $\theta_{p}$ is the interaction between treatment $p$ and characteristic $D .{ }^{10}$ We will focus on the primary outcome of hygienic latrine ownership unless otherwise noted, and will present results for

\footnotetext{
${ }^{10}$ For comparison with the group-level results, we estimate equation (2) with no household characteristics or interactions in Appendix Tables B10 (short-term) and B11 (medium-term). The results are very close to the corresponding group-level estimates in Tables 3 and 4, respectively.
} 
the monetary reward and public commitment treatments, with full regression results for all treatments in Appendix tables.

We first examine whether households' responsiveness differ by poverty, which we proxy by landlessness. We hypothesized that landless households would be less able to respond to the non-monetary arms but might benefit from cross-subsidization in the monetary arms. In fact, in the short term, landless households responded nearly identically, as shown in Figure 4a. (Regression results reported in Appendix Table C1.) In the medium term (Figure 4b), point estimates suggest some heterogeneity in response: both the fading of the effect of the monetary treatment and the sustained effect of the public commitment treatment is among landed households, although in neither case do the estimated interaction terms reach statistical significance (Appendix Table C2).

We also investigate heterogeneity by the household's baseline ownership status. Households are classified as owning none (the base category), owning a non-hygienic latrine, or owning a hygienic latrine. We hypothesized that households owning a non-hygienic or hygienic latrine at baseline would be relatively more responsive to the non-monetary treatments than households owning no latrine at baseline, since these households might need only minor improvements to reach (in the case of owners of non-hygienic latrines) or sustain (in the case of owners of hygienic latrines) hygienic status. Similarly for the monetary reward treatment, because the reward amount was not large relative to the cost of a new hygienic latrine, we expected larger effects in the higher baseline categories, although there was greater potential for cross-subsidization of households owning no latrine in the monetary reward arm.

These predictions largely hold in the medium term, although not in the short term. In the short term (Figure 5a, Appendix Table C3), the effects of both the monetary reward and public commitment treatment are similar across baseline ownership status categories. In the medium term (Figure 5b, Appendix Table C4), the point estimates indicate larger impacts among households owning a non-hygienic latrine at baseline, although these either do not 
reach statistical significance (monetary reward) or are only borderline statistically significant (public committment). That the public commitment treatment's effect is sustained into the medium term largely through its effect on this group suggests that modest improvements to existing latrines were more sustainable than major efforts to build a new, hygienic latrine quickly.

\section{Group Characteristics}

Ex post, we conducted an exploratory analysis of the association between group-level characteristics and the magnitude of treatment effects. Similar to equation 2, we estimate

$$
\begin{aligned}
y_{g v} & =\alpha_{0}+\alpha_{1} D_{g v} \\
& \left.+\sum_{p=1}^{4} \beta_{p} \cdot 1\left\{\text { Treat }_{v}=p\right\}+\sum_{p=1}^{4} \theta_{p} \cdot 1 \text { Treat }_{v}=p\right\} \times D_{g v} \\
& +\delta y_{0 g v}+\gamma \text { ShareLandless }_{g v}+\varphi_{u}+\varepsilon_{g v}
\end{aligned}
$$

where $y_{g v}$ is the outcome variable of interest for group $g$ in village $v, D_{g v}$ is a characteristic of group $g$ and all other variables are as defined in equation (2). The coefficient $\alpha_{1}$ represents the level effect of characteristic $D$, i.e., the association of $D$ with the outcome variable $y_{g v}$ in the comparison group, the coefficient $\beta_{p}$ represents the level effect of treatment $p$, i.e., the effect of treatment $p$ on groups with $D=0,{ }^{11}$ and the coefficient $\theta_{p}$ is the interaction between treatment $p$ and characteristic $D$.

We considered the following characteristics, which were relevant as proxies for resources available to the group, baseline sanitation status, or group social cohesion:

- Share of landless households in the group

- Baseline ownership of hygienic latrines

- Baseline ownership of non-hygienic latrines

\footnotetext{
${ }^{11}$ For continuous $D$, we de-mean the interaction variable so $\beta_{p}$ represents the effect of treatment $p$ on groups with the mean level of $D$ (Wainer 2000).
} 
- Baseline ownership of any latrine

- Whether the group contained an individual considered by others in the village to be a village leader

- Group size (number of households)

- Group density (the average number of households within $50 \mathrm{~m}$ of each household in the group)

- Two social network statistics calculated using baseline data on household relationships within the village

- Maximum eigenvalue of adjacency matrix, interpretable as the speed at which information will spread within the group

- The second eigenvalue of the stochastized adjacency matrix, interpretable as how segregated a network is, i.e., negatively related to the extent to which information will spread within the group

Overall, we do not find strong evidence of an association between these variables and the size of our estimated treatment effects. There is a weak negative association between the share of landless household in the group and the effectiveness of the monetary reward treatment, although only in the short term (Tables D1-D2). Contrary to our expectation, the presence of a village leader in a group is negatively associated with the effectiveness of the monetary reward and reward certificate treatments, although again only in the short term (Tables D9-D10). The effectiveness of the monetary reward treatment is negatively associated with the network segregation measure, once again in the short term only (Tables D17-D18). Given the large number of hypotheses tested and the relatively low power to detect interactions, we view these results as suggestive only.

\section{Conclusion}

While there has been widespread recognition in the development economics literature that investments in welfare-improving technologies with the potential to address important development challenges has remained puzzlingly low, scant attention has been paid to inter- 
dependencies in decision-making. We design a series of interventions to explore whether we can promote investments in a healthier technology to address an important public health externality by taking advantage of the fact that coordination schemes that help communities overcome collective action failures. The two specific strategies we tested were creating a joint financial liability by offering a joint monetary or non-monetary reward, and by encouraging community members to publicly commit to pursuing healthier behaviors in front of their neighbors, so that both their own, and their neighbors' health would improve.

We find that the monetary reward has the largest effect in the short term (3 months), increasing the share of households with hygienic latrines by 7.5 to 12.5 percentage points. The public commitment treatment lead to a 4.2 to $6.1 \mathrm{pp}$ increase in the same period. The effect of the monetary reward faded in the medium term (15 months), while the effect of the public commitment treatment persisted. We find that this difference is explained by households in the public commitment treatment maintaining improvements in publicly visible components of the latrine. We find little evidence of heterogeneity in impacts with respect to group characteristics.

Our results are immediately relevant for policymakers in South Asia and other developing countries struggling with the stubborn problem of low investment in improved sanitation and hygiene. They are also more broadly relevant for development economists studying the under-investment in a broader range of (seemingly beneficial) products, technologies and behaviors, including hand-washing and masks (Abaluck et al 2021) that became especially relevant during the COVID-19 pandemic. We highlight decision inter-dependencies as a driving factor for adoption of product categories that may impose externalities on other members of society, or are strategic complements in investment. Our direct comparison of incentives and rewards (both monetary and in-kind) against public commitments contribute to an even broader literature in public economics on how personal and social incentives are shaped. 


\section{References}

Andrés, L., B. Briceño, C. Chase, and J. A. Echenique (2017). "Sanitation and externalities: evidence from early childhood health in rural India." Journal of Water, Sanitation and Hygiene for Development 7.2, pp. 272-289. DOI: 10.2166/washdev .2017.143.

Ashraf, N., J. Berry, and J. M. Shapiro (2010). "Can Higher Prices Stimulate Product Use? Evidence from a Field Experiment in Zambia." American Economic Review 100.5, pp. 2383-2413. DOI: 10.1257/aer.100.5.2383.

Augsburg, B. and P. A. Rodríguez-Lesmes (2018). "Sanitation and child health in India." World Development 107, pp. 22-39. DOI: 10.1016/j .worlddev.2018.02.005.

Banerjee, A. and S. Mullainathan (2010). "The Shape of Temptation: Implications for the Economics Lives of the Poor." NBER Working Paper 15973. DOI: 10.3386/w20997.

BenYishay, A., A. Fraker, et al. (2017). "Microcredit and willingness to pay for environmental quality: Evidence from a randomized-controlled trial of finance for sanitation in rural Cambodia." Journal of Environmental Economics and Management 86, pp. 121-140. DOI: $10.1016 / j \cdot j$ jeem.2016.11.004.

BenYishay, A. and A. M. Mobarak (2019). "Social Learning and Incentives for Experimentation and Communication." The Review of Economic Studies 86.3, pp. 976-1009. DOI: 10.1093/ restud/rdy039.

Bryan, G., S. Chowdhury, and A. M. Mobarak (2014). "Underinvestment in a Profitable Technology: The Case of Seasonal Migration in Bangladesh." Econometrica 82.5, pp. 16711748. DOI: $10.3982 /$ ECTA10489.

Cameron, L., P. Santos, M. Thomas, and J. Albert (2021). "Sanitation, Financial Incentives and Health Spillovers: A Cluster Randomised Trial." Journal of Health Economics, p. 102456. DOI: $10.1016 / j \cdot j$ healeco.2021.102456.

Chambers, R. and G. Von Medeazza (2013). "Sanitation and Stunting in India: Undernutrition's Blind Spot." Economic and Political Weekly 48.25, pp. 15-18. https://www.jstor. org/stable/23527965.

Coffey, D. et al. (2014). "Revealed Preference for Open Defecation." Economic and Political Weekly 49.38, pp. 43-55. http: //www. epw. in/special-articles/revealedpreference-open-defecation.html.

Cole, S., D. Stein, and J. Tobacman (2014). "Dynamics of Demand for Index Insurance: Evidence from a Long-Run Field Experiment." American Economic Review 104.5, pp. 28490. DOI: $10.1257 /$ aer.104.5.284.

Deutschmann, J. W., M. Lipscomb, L. Schechter, and S. J. Zhu (2021). "Spillovers without Social Interactions in Urban Sanitation." SSRN Scholarly Paper 3790865. DOI: 10.2139/ ssrn. 3790865 . 
Duflo, E., M. Kremer, and J. Robinson (2011). "Nudging Farmers to Use Fertilizer: Theory and Experimental Evidence from Kenya." American Economic Review 101.6, pp. 2350-2390. DOI: $10.1257 /$ aer.101.6.2350.

Dupas, P. and J. Robinson (2013). "Savings Constraints and Microenterprise Development: Evidence from a Field Experiment in Kenya." American Economic Journal: Applied Economics 5.1, pp. 163-192. DOI: 10.1257/app.5.1.163.

Foster, A. D. and M. R. Rosenzweig (1995). "Learning by doing and learning from others: Human capital and technical change in agriculture." Journal of Political Economy 103.6. http://www . jstor .org/stable/2138708.

Foster, A. D. and M. R. Rosenzweig (2010). "Microeconomics of Technology Adoption." Annual Review of Economics 2.1, pp. 395-424. DOI: 10.1146/annurev .economics.102308. 124433.

Fuller, J. A., E. Villamor, W. Cevallos, J. Trostle, and J. N. Eisenberg (2016). "I get height with a little help from my friends: herd protection from sanitation on child growth in rural Ecuador." International Journal of Epidemiology 45.2, pp. 460-469. DOI: 10.1093/ije/ dyv368.

Gertler, P., M. Shah, M. L. Alzua, L. Cameron, S. Martinez, and S. Patil (2015). "How Does Health Promotion Work? Evidence From The Dirty Business of Eliminating Open Defecation." NBER Working Paper 20997. DOI: 10.3386/w20997.

Gollwitzer, P. M. and V. Brandstätter (1997). "Implementation intentions and effective goal pursuit." Journal of Personality and Social Psychology 73.1, pp. 186-199. DoI: 10.1037/ 0022-3514.73.1.186.

Guiteras, R. P., J. Levinsohn, and A. M. Mobarak (2015). "Encouraging sanitation investment in the developing world: A cluster-randomized trial." Science 348.6237, pp. 903-906. DOI: 10.1126/science. aaa0491.

Hanchett, S., M. H. Khan, L. Krieger, and C. Kullmann (2011). "Sustainability of sanitation in rural Bangladesh." In: The Future of Water Sanitation and Hygiene: Innovation, Adaptation and Engagement in a Changing World. Loughborough, UK. http://wedc.lboro.ac.uk/ resources/conference/35/Hanchett-S-1036.pdf.

Hathi, P., S. Haque, L. Pant, D. Coffey, and D. Spears (2017). "Place and Child Health: The Interaction of Population Density and Sanitation in Developing Countries." Demography 54.1, pp. 337-360. DOI: 10.1007/s13524-016-0538-y.

MacKinnon, J. G. and M. D. Webb (2017). "Wild Bootstrap Inference for Wildly Different Cluster Sizes." Journal of Applied Econometrics 32.2, pp. 233-254. DOI: 10.1002/jae. 2508.

Maluccio, J. A., J. Hoddinott, J. R. Behrman, R. Martorell, A. R. Quisumbing, and A. D. Stein (2009). "The Impact of Improving Nutrition During Early Childhood on Education among Guatemalan Adults." The Economic Journal 119.537, pp. 734-763. DOI: 10.1111/j.1468$0297.2009 .02220 . x$. 
Mara, D., J. Lane, B. Scott, and D. Trouba (2010). "Sanitation and Health." PLoS Med 7.11, e1000363. DOI: 10.1371/journal.pmed.1000363.

McKenzie, D. (2012). "Beyond baseline and follow-up: The case for more T in experiments." Journal of Development Economics 99.2, pp. 210-221. DOI: 10.1016/j.jdeveco.2012.01. 002.

Munshi, K. (2003). "Networks in the Modern Economy: Mexican Migrants in the United States Labor Market." Quarterly Journal of Economics 118.2, pp. 549-599. https://www . jstor.org/stable/25053914.

Muralidharan, K., M. Romero, and K. Wüthrich (2020). "Factorial Designs, Model Selection, and (Incorrect) Inference in Randomized Experiments." NBER Working Paper 26562. DOI: $10.3386 / \mathrm{w} 26562$.

Orgill-Meyer, J. et al. (2019). "Long-term impact of a community-led sanitation campaign in India, 2005-2016." Bulletin of the World Health Organization 97.8, 523-533A. DoI: 10.2471/BLT.18.221572.

Pakhtigian, E. L., K. L. Dickinson, J. Orgill-Meyer, and S. K. Pattanayak (2021). "Sustaining latrine use: Peers, policies, and sanitation behaviors." Working Paper.

Pattanayak, S. K. et al. (2009). "Shame or subsidy revisited: social mobilization for sanitation in Orissa, India." Bulletin of the World Health Organization 87.8, pp. 580-587. DOI: 10.2471/BLT.08.057422.

Pickering, A. J., H. Djebbari, C. Lopez, M. Coulibaly, and M. L. Alzua (2015). "Effect of a community-led sanitation intervention on child diarrhoea and child growth in rural Mali: a cluster-randomised controlled trial." The Lancet Global Health 3.11, e701-e711. DOI: 10.1016/S2214-109X (15)00144-8.

Prüss-Ustün, A. et al. (2014). "Burden of disease from inadequate water, sanitation and hygiene in low- and middle-income settings: a retrospective analysis of data from 145 countries." Tropical Medicine \& International Health 19.8, pp. 894-905. DOI: 10.1111/tmi.12329.

Roodman, D., M. Ø. Nielsen, J. G. MacKinnon, and M. D. Webb (2019). "Fast and wild: Bootstrap inference in Stata using boottest." Stata Journal 19.1, pp. 4-60. DoI: 10.1177/ 1536867 X19830877.

Schelling, T. C. (1960). The Strategy of Conflict. Cambridge: Harvard University Press.

Smets, S., B. Malde, S. Giunti, B. Caeyers, and B. Augsburg (2021). "Labelled loans and human capital investments." IFS Working Paper 21/09. Institute for Fiscal Studies. DOI: 10.1920/wp. ifs.2021.921.

Spears, D. (2013). "How Much International Variation in Child Height Can Sanitation Explain?" Policy Research Working Paper 6351. World Bank. DOI: 10.1596/1813-94506351. 
Udry, C. (2010). "The economics of agriculture in Africa: Notes toward a research program." African Journal of Agricultural and Resource Economics 05.1, pp. 1-16. DOI: 10.22004/ ag. econ. 156665.

Wainer, H. (2000). "The Centercept: An Estimable and Meaningful Regression Parameter." Psychological Science 11.5, pp. 434-436. DOI: 10.1111/1467-9280.00284.

WHO and UNICEF (2017). "Progress on Drinking Water, Sanitation and Hygiene: 2017 update and SDG baselines." Technical Report. Geneva: Joint Monitoring Programme of World Health Organization (WHO) and the United Nations Children's Fund (UNICEF). http://www.who.int/water_sanitation_health/publications/jmp-2017/en/. 
Table 1: Randomization

\begin{tabular}{|l|c|c|c|}
\hline & \multicolumn{3}{|c|}{ Commitment } \\
\hline Reward & None & Private & Public \\
\hline \hline None & A: 8 villages; 121 groups & B: 11 villages; 177 groups & C: 11 villages; 69 groups \\
& 1,898 households $(9.8 \%)$ & 2,626 households $(13.6 \%)$ & 1,088 households $(5.6 \%)$ \\
\hline Monetary & D: 10 villages; 79 groups & E: 5 villages; 58 groups & F: 9 villages; 97 groups \\
& 1,159 households (6.0\%) & 885 households (4.6\%) & 1,568 households (8.1\%) \\
\hline Certificate & G: 12 villages; 145 groups & H: 9 villages; 110 groups & I: 9 villages; 124 groups \\
& 2,314 households (12.0\%) & 1,694 households $(8.8 \%)$ & 1,970 households $(10.2 \%)$ \\
\hline
\end{tabular}

\begin{tabular}{|l|l|}
\hline Pure Control & J: 23 villages; 256 groups \\
& 4,069 households $(21.1 \%)$ \\
\hline
\end{tabular}


Table 2: Descriptive Statistics and Balance Tests

\begin{tabular}{|c|c|c|c|c|c|c|c|c|}
\hline \multirow{3}{*}{ Treatment: } & \multirow[b]{2}{*}{ All } & \multirow{2}{*}{$\begin{array}{l}\text { Pure } \\
\text { Control }\end{array}$} & \multirow{2}{*}{$\begin{array}{l}\text { Basic } \\
\text { Only }\end{array}$} & \multicolumn{2}{|c|}{ Reward } & \multicolumn{2}{|c|}{ Commitment } & \multirow{3}{*}{$\begin{array}{c}\text { Joint } \\
p \text {-val. } \\
(8)\end{array}$} \\
\hline & & & & Monetary & Certificate & Private & Public & \\
\hline & $\begin{array}{c}\text { Mean } \\
\text { (S.D.) } \\
\text { (1) }\end{array}$ & $\begin{array}{c}\text { Mean } \\
\text { (S.D.) } \\
(2)\end{array}$ & $\begin{array}{c}\text { Mean } \\
\text { (S.D.) } \\
\text { (3) }\end{array}$ & $\begin{array}{c}\text { Diff } \\
{[\text { S.E. }]} \\
(4)\end{array}$ & $\begin{array}{c}\text { Diff } \\
\text { [S.E. }] \\
(5)\end{array}$ & $\begin{array}{c}\text { Diff } \\
\text { [S.E. }] \\
(6)\end{array}$ & $\begin{array}{c}\text { Diff } \\
\text { [S.E. }] \\
(7)\end{array}$ & \\
\hline \multicolumn{9}{|l|}{ Group characteristics: } \\
\hline Group size (num. HH) & $\begin{array}{l}15.59 \\
(2.74)\end{array}$ & $\begin{array}{l}15.89 \\
(2.78)\end{array}$ & $\begin{array}{l}15.69 \\
(2.48)\end{array}$ & $\begin{array}{l}-0.25 \\
{[0.51]}\end{array}$ & $\begin{array}{c}0.09 \\
{[0.46]}\end{array}$ & $\begin{array}{l}-0.60 \\
{[0.47]}\end{array}$ & $\begin{array}{c}0.27 \\
{[0.48]}\end{array}$ & 0.286 \\
\hline Share landless & $\begin{array}{l}0.350 \\
(0.243)\end{array}$ & $\begin{array}{c}0.363 \\
(0.251)\end{array}$ & $\begin{array}{c}0.312 \\
(0.208)\end{array}$ & $\begin{array}{c}0.054 \\
{[0.042]}\end{array}$ & $\begin{array}{c}0.025 \\
{[0.033]}\end{array}$ & $\begin{array}{c}0.031 \\
{[0.034]}\end{array}$ & $\begin{array}{c}0.027 \\
{[0.036]}\end{array}$ & 0.852 \\
\hline $\begin{array}{l}\text { Regular open defecation by adults } \\
\text { (HH self-report) }\end{array}$ & $\begin{array}{c}0.263 \\
(0.250)\end{array}$ & $\begin{array}{l}0.270 \\
(0.251)\end{array}$ & $\begin{array}{c}0.199 \\
(0.224)\end{array}$ & $\begin{array}{l}0.082^{*} \\
{[0.045]}\end{array}$ & $\begin{array}{c}0.035 \\
{[0.045]}\end{array}$ & $\begin{array}{c}0.073 \\
{[0.049]}\end{array}$ & $\begin{array}{c}0.049 \\
{[0.044]}\end{array}$ & 0.675 \\
\hline Density (mean num. HH within 50m) & $\begin{array}{l}12.33 \\
(6.07)\end{array}$ & $\begin{array}{l}11.69 \\
(5.74)\end{array}$ & $\begin{array}{l}13.67 \\
(6.58)\end{array}$ & $\begin{array}{l}-1.81 \\
{[1.39]}\end{array}$ & $\begin{array}{l}-1.03 \\
{[1.43]}\end{array}$ & $\begin{array}{l}-0.87 \\
{[1.43]}\end{array}$ & $\begin{array}{l}-1.18 \\
{[1.55]}\end{array}$ & 0.884 \\
\hline Village leader in group & $\begin{array}{c}0.153 \\
(0.360)\end{array}$ & $\begin{array}{c}0.156 \\
(0.364)\end{array}$ & $\begin{array}{c}0.116 \\
(0.321)\end{array}$ & $\begin{array}{l}0.072^{* *} \\
{[0.035]}\end{array}$ & $\begin{array}{c}0.032 \\
{[0.032]}\end{array}$ & $\begin{array}{c}0.009 \\
{[0.032]}\end{array}$ & $\begin{array}{l}0.060^{*} \\
{[0.032]}\end{array}$ & 0.376 \\
\hline \multicolumn{9}{|l|}{ Baseline latrine ownership: } \\
\hline Owns no latrine & $\begin{array}{c}0.403 \\
(0.202)\end{array}$ & $\begin{array}{c}0.394 \\
(0.195)\end{array}$ & $\begin{array}{c}0.377 \\
(0.188)\end{array}$ & $\begin{array}{c}0.014 \\
{[0.026]}\end{array}$ & $\begin{array}{c}0.012 \\
{[0.029]}\end{array}$ & $\begin{array}{c}0.040 \\
{[0.033]}\end{array}$ & $\begin{array}{c}0.008 \\
{[0.029]}\end{array}$ & 0.187 \\
\hline Owns any latrine & $\begin{array}{c}0.597 \\
(0.202)\end{array}$ & $\begin{array}{c}0.606 \\
(0.195)\end{array}$ & $\begin{array}{c}0.623 \\
(0.188)\end{array}$ & $\begin{array}{c}-0.014 \\
{[0.026]}\end{array}$ & $\begin{array}{l}-0.012 \\
{[0.029]}\end{array}$ & $\begin{array}{c}-0.040 \\
{[0.033]}\end{array}$ & $\begin{array}{c}-0.008 \\
{[0.029]}\end{array}$ & 0.187 \\
\hline Owns non-hygienic latrine & $\begin{array}{c}0.214 \\
(0.154)\end{array}$ & $\begin{array}{c}0.244 \\
(0.155)\end{array}$ & $\begin{array}{c}0.212 \\
(0.151)\end{array}$ & $\begin{array}{c}0.000 \\
{[0.024]}\end{array}$ & $\begin{array}{l}-0.015 \\
{[0.025]}\end{array}$ & $\begin{array}{l}-0.007 \\
{[0.025]}\end{array}$ & $\begin{array}{c}0.001 \\
{[0.026]}\end{array}$ & 0.903 \\
\hline Owns hygienic latrine & $\begin{array}{c}0.397 \\
(0.218)\end{array}$ & $\begin{array}{c}0.374 \\
(0.201)\end{array}$ & $\begin{array}{c}0.435 \\
(0.203)\end{array}$ & $\begin{array}{c}-0.023 \\
{[0.040]}\end{array}$ & $\begin{array}{c}-0.006 \\
{[0.044]}\end{array}$ & $\begin{array}{c}-0.043 \\
{[0.050]}\end{array}$ & $\begin{array}{c}-0.016 \\
{[0.041]}\end{array}$ & 0.625 \\
\hline \multicolumn{9}{|l|}{ Baseline latrine access: } \\
\hline No latrine access & $\begin{array}{c}0.211 \\
(0.223)\end{array}$ & $\begin{array}{c}0.196 \\
(0.205)\end{array}$ & $\begin{array}{c}0.170 \\
(0.209)\end{array}$ & $\begin{array}{c}0.042 \\
{[0.039]}\end{array}$ & $\begin{array}{c}0.024 \\
{[0.039]}\end{array}$ & $\begin{array}{c}0.061 \\
{[0.043]}\end{array}$ & $\begin{array}{c}0.028 \\
{[0.040]}\end{array}$ & 0.525 \\
\hline Access to any latrine & $\begin{array}{c}0.789 \\
(0.223)\end{array}$ & $\begin{array}{c}0.804 \\
(0.205)\end{array}$ & $\begin{array}{c}0.830 \\
(0.209)\end{array}$ & $\begin{array}{c}-0.042 \\
{[0.039]}\end{array}$ & $\begin{array}{c}-0.024 \\
{[0.039]}\end{array}$ & $\begin{array}{c}-0.061 \\
{[0.043]}\end{array}$ & $\begin{array}{c}-0.028 \\
{[0.040]}\end{array}$ & 0.525 \\
\hline Access to hygienic latrine & $\begin{array}{c}0.491 \\
(0.257)\end{array}$ & $\begin{array}{c}0.466 \\
(0.242)\end{array}$ & $\begin{array}{c}0.533 \\
(0.232)\end{array}$ & $\begin{array}{c}-0.031 \\
{[0.046]}\end{array}$ & $\begin{array}{c}0.001 \\
{[0.052]}\end{array}$ & $\begin{array}{l}-0.053 \\
{[0.056]}\end{array}$ & $\begin{array}{l}-0.015 \\
{[0.048]}\end{array}$ & 0.496 \\
\hline \multicolumn{9}{|l|}{ Sample sizes: } \\
\hline Villages & 107 & 23 & 8 & 24 & 30 & 25 & 29 & \\
\hline Groups & 1,236 & 256 & 121 & 234 & 379 & 345 & 290 & \\
\hline Households & 19,271 & 4,069 & 1,898 & 3,612 & 5,978 & 5,205 & 4,626 & \\
\hline
\end{tabular}

Notes: this table presents summary statistics (means and standard deviations) of key baseline variables for all villages (Column 1), pure control villages (Column 2) and villages where groups received only the basic health messaging treatment (Column 3). Standard deviations are in parentheses. Columns 4-7 show estimated coefficients for indicators for the village-level treatments (monetary reward, reward certificate, private commitment, public commitment) in regressions where the baseline variable is the dependent variable, and the basic health messaging treatment is the omitted category. Estimated standard errors robust to clustering at the village level are in brackets. Column 8 shows the p-value on a joint F-test of significance of the treatment indicators. Sample sizes do not sum because villages may be assigned to one reward treatment, one commitment treatment, one from each category, or neither. (See discussion of experimental design in the text.) ${ }^{*} p<0.10,{ }^{* *} p<0.05,{ }^{* * *} p<0.01$. 
Table 3: Short-term Effects: Hygienic Latrine Ownership

\begin{tabular}{|c|c|c|c|c|}
\hline & (1) & $(2)$ & $(3)$ & (4) \\
\hline Monetary reward & $\begin{array}{c}0.100^{* *} \\
(0.045) \\
{[0.007,0.198]}\end{array}$ & $\begin{array}{c}0.125^{* * *} \\
(0.035) \\
{[0.050,0.204]}\end{array}$ & $\begin{array}{c}0.072^{* * *} \\
(0.015) \\
{[0.039,0.105]}\end{array}$ & $\begin{array}{c}0.075^{* * *} \\
(0.015) \\
{[0.043,0.106]}\end{array}$ \\
\hline Reward certificate & $\begin{array}{c}0.051 \\
(0.044) \\
{[-0.050,0.151]}\end{array}$ & $\begin{array}{c}0.043 \\
(0.037) \\
{[-0.048,0.129]}\end{array}$ & $\begin{array}{c}0.009 \\
(0.012) \\
{[-0.019,0.037]}\end{array}$ & $\begin{array}{c}0.010 \\
(0.012) \\
{[-0.017,0.037]}\end{array}$ \\
\hline Private commitment & $\begin{array}{c}0.002 \\
(0.044) \\
{[-0.098,0.104]}\end{array}$ & $\begin{array}{c}0.010 \\
(0.038) \\
{[-0.074,0.100]}\end{array}$ & $\begin{array}{c}0.011 \\
(0.012) \\
{[-0.017,0.038]}\end{array}$ & $\begin{array}{c}0.010 \\
(0.012) \\
{[-0.017,0.037]}\end{array}$ \\
\hline Public commitment & $\begin{array}{c}0.056 \\
(0.041) \\
{[-0.034,0.143]}\end{array}$ & $\begin{array}{c}0.061 \\
(0.037) \\
{[-0.023,0.144]}\end{array}$ & $\begin{array}{c}0.042^{* * *} \\
(0.015) \\
{[0.008,0.077]}\end{array}$ & $\begin{array}{c}0.042^{* * *} \\
(0.015) \\
{[0.008,0.077]}\end{array}$ \\
\hline Baseline share owning hyg. lat. & & & $\begin{array}{c}0.748^{* * *} \\
(0.023)\end{array}$ & $\begin{array}{c}0.720^{* * *} \\
(0.023)\end{array}$ \\
\hline Share of households landless & & & & $\begin{array}{c}-0.067^{* * *} \\
(0.017)\end{array}$ \\
\hline Union FEs & No & Yes & Yes & Yes \\
\hline Number of groups & 980 & 980 & 980 & 980 \\
\hline Number of villages & 84 & 84 & 84 & 84 \\
\hline Omitted category mean & 0.451 & 0.451 & 0.451 & 0.451 \\
\hline Omitted category S.D. & $(0.189)$ & $(0.189)$ & $(0.189)$ & $(0.189)$ \\
\hline
\end{tabular}

Notes: the dependent variable is the share of households in the group with a hygienic latrine in the short term (at the time of assessment). Observations (groups) are weighted by the number of households. The sample excludes pure control villages, so the omitted category consists of groups that received basic health message on hygienic latrines and sanitation practices. Standard errors clustered at the village level in parentheses. Wild cluster bootstrap (9,999 repetitions, Webb weights) $95 \%$ confidence intervals, resampling at the village level, in brackets for the coefficients of interest. ${ }^{*} p<0.10,{ }^{* *} p<0.05,{ }^{* * *} p<0.01$. 
Table 4: Medium-term Effects: Hygienic Latrine Ownership

\begin{tabular}{|c|c|c|c|c|}
\hline & (1) & $(2)$ & $(3)$ & (4) \\
\hline Monetary reward & $\begin{array}{c}0.041 \\
(0.036) \\
{[-0.036,0.119]}\end{array}$ & $\begin{array}{c}0.052^{*} \\
(0.030) \\
{[-0.014,0.119]}\end{array}$ & $\begin{array}{c}0.010 \\
(0.019) \\
{[-0.030,0.051]}\end{array}$ & $\begin{array}{c}0.015 \\
(0.019) \\
{[-0.026,0.054]}\end{array}$ \\
\hline Reward certificate & $\begin{array}{c}0.045 \\
(0.038) \\
{[-0.043,0.131]}\end{array}$ & $\begin{array}{c}0.042 \\
(0.035) \\
{[-0.041,0.123]}\end{array}$ & $\begin{array}{c}0.016 \\
(0.023) \\
{[-0.037,0.066]}\end{array}$ & $\begin{array}{c}0.018 \\
(0.022) \\
{[-0.032,0.066]}\end{array}$ \\
\hline Private commitment & $\begin{array}{c}0.011 \\
(0.040) \\
{[-0.084,0.101]}\end{array}$ & $\begin{array}{c}0.012 \\
(0.039) \\
{[-0.079,0.101]}\end{array}$ & $\begin{array}{c}0.012 \\
(0.025) \\
{[-0.046,0.067]}\end{array}$ & $\begin{array}{c}0.011 \\
(0.024) \\
{[-0.046,0.065]}\end{array}$ \\
\hline Public commitment & $\begin{array}{c}0.075^{* *} \\
(0.032) \\
{[0.006,0.145]}\end{array}$ & $\begin{array}{c}0.076^{* * *} \\
(0.029) \\
{[0.014,0.137]}\end{array}$ & $\begin{array}{c}0.061^{* * *} \\
(0.017) \\
{[0.026,0.096]}\end{array}$ & $\begin{array}{c}0.061^{* * *} \\
(0.017) \\
{[0.025,0.096]}\end{array}$ \\
\hline Baseline share owning hyg. lat. & & & $\begin{array}{c}0.578^{* * *} \\
(0.036)\end{array}$ & $\begin{array}{c}0.533^{* * *} \\
(0.039)\end{array}$ \\
\hline Share of households landless & & & & $\begin{array}{c}-0.107^{* * *} \\
(0.032)\end{array}$ \\
\hline Union FEs & No & Yes & Yes & Yes \\
\hline Number of groups & 979 & 979 & 979 & 979 \\
\hline Number of villages & 84 & 84 & 84 & 84 \\
\hline Omitted category mean & 0.544 & 0.544 & 0.544 & 0.544 \\
\hline Omitted category S.D. & $(0.255)$ & $(0.255)$ & $(0.255)$ & $(0.255)$ \\
\hline
\end{tabular}

Notes: the dependent variable is the share of households in the group with a hygienic latrine in the medium term (12-15 months after assessment). Observations (groups) are weighted by the number of households. The sample excludes pure control villages, so the omitted category consists of groups that received basic health message on hygienic latrines and sanitation practices. Standard errors clustered at the village level in parentheses. Wild cluster bootstrap (9,999 repetitions, Webb weights) $95 \%$ confidence intervals, resampling at the village level, in brackets for the coefficients of interest. ${ }^{*} p<0.10,{ }^{* *} p<0.05,{ }^{* * *} p<0.01$. 
Table 5: Short-term Effects: Latrine Components Functional and Unbroken

\begin{tabular}{lccc}
\hline & $(1)$ & $(2)$ & $(3)$ \\
& Slab & Seal & Pit Cover and Rings \\
\hline Monetary reward & $0.029^{*}$ & $0.058^{* * *}$ & $0.070^{* * *}$ \\
& $(0.017)$ & $(0.014)$ & $(0.021)$ \\
Reward certificate & 0.011 & 0.009 & 0.027 \\
& $(0.016)$ & $(0.011)$ & $(0.019)$ \\
Private commitment & -0.006 & 0.003 & 0.006 \\
& $(0.015)$ & $(0.011)$ & $(0.020)$ \\
Public commitment & 0.002 & 0.018 & $0.039^{*}$ \\
Baseline share owning hyg. lat. & $0.539^{* * *}$ & $0.764^{* * *}$ & $0.482^{* * *}$ \\
Share of households landless & $(0.035)$ & $(0.022)$ & $(0.041)$ \\
& $-0.058^{* *}$ & $-0.068^{* * *}$ & -0.021 \\
Union FEs & $(0.023)$ & $(0.019)$ & $(0.026)$ \\
\hline Number of households & Yes & Yes & Yes \\
Number of groups & 14,430 & 14,094 & 14,430 \\
Number of villages & 980 & 980 & 980 \\
Omitted category mean & 84 & 84 & 84 \\
\hline
\end{tabular}

Notes: this table shows estimated treatment effects on indicators for whether the household owns a latrine with the component indicated in the column header functional and unbroken in the short term (at the time of assessment). The sample excludes pure control villages, so the omitted category consists of households in groups that received the basic health messaging treatment. Standard errors clustered at the village level in parentheses. ${ }^{*} p<0.10,{ }^{* *} p<0.05,{ }^{* * *} p<0.01$. 
Table 6: Medium-term Effects: Latrine Components Functional and Unbroken

\begin{tabular}{lccc}
\hline & $(1)$ & $(2)$ & $(3)$ \\
& Slab & Seal & Pit Cover and Rings \\
\hline Monetary reward & -0.008 & 0.025 & 0.003 \\
& $(0.017)$ & $(0.022)$ & $(0.023)$ \\
Reward certificate & 0.016 & 0.024 & 0.023 \\
& $(0.019)$ & $(0.023)$ & $(0.027)$ \\
Private commitment & 0.002 & -0.001 & -0.003 \\
& $(0.020)$ & $(0.025)$ & $(0.029)$ \\
Public commitment & 0.014 & 0.016 & $0.049^{* *}$ \\
Baseline share owning hyg. lat. & $0.432^{* * *}$ & $0.621^{* * *}$ & $0.343^{* * *}$ \\
Share of households landless & $(0.044)$ & $(0.038)$ & $(0.045)$ \\
& $-0.136^{* * *}$ & $-0.141^{* * *}$ & $-0.139^{* * *}$ \\
Union FEs & $(0.029)$ & $(0.032)$ & $(0.027)$ \\
\hline Number of households & Yes & Yes & Yes \\
Number of groups & 6,282 & 6,206 & 6,269 \\
Number of villages & 979 & 979 & 979 \\
Omitted category mean & 84 & 84 & 84 \\
\hline
\end{tabular}

Notes: this table shows estimated treatment effects on indicators for whether the household owns a latrine with the component indicated in the column header functional and unbroken in the medium term (12-15 months after assessment). The sample excludes pure control villages, so the omitted category consists of households in groups that received the basic health messaging treatment. Standard errors clustered at the village level in parentheses. ${ }^{*} p<0.10,{ }^{* *} p<0.05,{ }^{* * *} p<0.01$. 
Table 7: Short-term Effects: Latrine Condition

\begin{tabular}{lccccc}
\hline & $(1)$ & $(2)$ & $(3)$ & $(4)$ & $(5)$ \\
& No Bad Smell & No Leaks & No Flies & Water & Soap \\
\hline Monetary reward & $0.083^{* * *}$ & $0.051^{* * *}$ & $0.176^{* * *}$ & $0.096^{* * *}$ & $0.079^{* * *}$ \\
& $(0.023)$ & $(0.018)$ & $(0.024)$ & $(0.019)$ & $(0.019)$ \\
Reward certificate & -0.022 & 0.009 & $0.053^{* * *}$ & -0.001 & -0.001 \\
& $(0.026)$ & $(0.018)$ & $(0.019)$ & $(0.017)$ & $(0.021)$ \\
Private commitment & -0.027 & 0.005 & 0.024 & 0.018 & 0.026 \\
& $(0.026)$ & $(0.018)$ & $(0.019)$ & $(0.018)$ & $(0.023)$ \\
Public commitment & 0.037 & $0.033^{*}$ & 0.029 & $-0.030^{*}$ & 0.011 \\
& $(0.023)$ & $(0.020)$ & $(0.022)$ & $(0.018)$ & $(0.017)$ \\
Baseline share owning hyg. lat. & $0.500^{* * *}$ & $0.455^{* * *}$ & $0.604^{* * *}$ & $0.539^{* * *}$ & $0.486^{* * *}$ \\
& $(0.031)$ & $(0.032)$ & $(0.032)$ & $(0.029)$ & $(0.035)$ \\
Share of households landless & -0.023 & -0.005 & -0.020 & $-0.096^{* * *}$ & $-0.127^{* * *}$ \\
& $(0.024)$ & $(0.028)$ & $(0.024)$ & $(0.021)$ & $(0.023)$ \\
Union FEs & Yes & Yes & Yes & Yes & Yes \\
\hline Number of households & 14,426 & 14,427 & 14,414 & 14,150 & 14,147 \\
Number of groups & 980 & 980 & 980 & 980 & 980 \\
Number of villages & 84 & 84 & 84 & 84 & 84 \\
Omitted category mean & 0.323 & 0.614 & 0.340 & 0.398 & 0.299 \\
\hline
\end{tabular}

Notes: this table shows estimated treatment effects on indicators of the household latrine condition noted in the column header. in the short term (at the time of assessment). The sample excludes pure control villages, so the omitted category consists of households in groups that received the basic health messaging treatment. Standard errors clustered at the village level in parentheses. ${ }^{*} p<0.10,{ }^{* *} p<0.05,{ }^{* * *} p<0.01$. 
Table 8: Medium-term Effects: Latrine Condition

\begin{tabular}{lccccc}
\hline & $(1)$ & $(2)$ & $(3)$ & $(4)$ & $(5)$ \\
& No Bad Smell & No Leaks & No Flies & Water & Soap \\
\hline Monetary reward & -0.056 & 0.016 & -0.001 & 0.027 & 0.028 \\
& $(0.042)$ & $(0.019)$ & $(0.037)$ & $(0.028)$ & $(0.029)$ \\
Reward certificate & $-0.065^{*}$ & 0.012 & $-0.093^{*}$ & 0.009 & $0.044^{*}$ \\
& $(0.033)$ & $(0.021)$ & $(0.054)$ & $(0.030)$ & $(0.025)$ \\
Private commitment & -0.001 & 0.004 & -0.069 & -0.005 & 0.029 \\
& $(0.034)$ & $(0.023)$ & $(0.057)$ & $(0.032)$ & $(0.028)$ \\
Public commitment & $0.081^{* *}$ & $0.035^{* *}$ & 0.023 & 0.022 & 0.026 \\
& $(0.039)$ & $(0.018)$ & $(0.042)$ & $(0.025)$ & $(0.026)$ \\
Baseline share owning hyg. lat. & $0.236^{* * *}$ & $0.334^{* * *}$ & $0.221^{* * *}$ & $0.447^{* * *}$ & $0.402^{* * *}$ \\
& $(0.050)$ & $(0.037)$ & $(0.057)$ & $(0.055)$ & $(0.052)$ \\
Share of households landless & $-0.087^{* * *}$ & $-0.135^{* * *}$ & $-0.140^{* * *}$ & $-0.166^{* * *}$ & $-0.159^{* * *}$ \\
& $(0.033)$ & $(0.030)$ & $(0.040)$ & $(0.037)$ & $(0.042)$ \\
Union FEs & Yes & Yes & Yes & Yes & Yes \\
\hline Number of households & 6,284 & 6,282 & 6,280 & 6,015 & 6,282 \\
Number of groups & 979 & 979 & 979 & 979 & 979 \\
Number of villages & 84 & 84 & 84 & 84 & 84 \\
Omitted category mean & 0.314 & 0.700 & 0.417 & 0.534 & 0.387 \\
\hline
\end{tabular}

Notes: this table shows estimated treatment effects on indicators of the household latrine condition noted in the column header. in the medium term (12-15 months after assessment). The sample excludes pure control villages, so the omitted category consists of households in groups that received the basic health messaging treatment. Standard errors clustered at the village level in parentheses. ${ }^{*} p<0.10,{ }^{* *} p<0.05,{ }^{* * *} p<0.01$. 
Table 9: Short-term Effects: Assistance from others in group

\begin{tabular}{lcccccc}
\hline & $(1)$ & $(2)$ & $(3)$ & $(4)$ & $(5)$ & $(6)$ \\
& Any & Advice or info. & Materials, cash, labor & Privately & Publicly & Pressure \\
\hline Monetary reward & $0.141^{* * *}$ & $0.135^{* * *}$ & $0.006^{* * *}$ & 0.036 & $0.131^{* * *}$ & $0.116^{* * *}$ \\
& $(0.032)$ & $(0.032)$ & $(0.002)$ & $(0.026)$ & $(0.030)$ & $(0.031)$ \\
Reward certificate & $0.079^{* *}$ & $0.077^{* *}$ & -0.000 & 0.037 & $0.080^{* *}$ & $0.034^{*}$ \\
& $(0.036)$ & $(0.037)$ & $(0.001)$ & $(0.026)$ & $(0.040)$ & $(0.019)$ \\
Private commitment & $0.087^{* *}$ & $0.086^{* *}$ & -0.000 & 0.018 & $0.081^{*}$ & 0.019 \\
& $(0.039)$ & $(0.040)$ & $(0.001)$ & $(0.027)$ & $(0.043)$ & $(0.020)$ \\
Public commitment & $0.065^{*}$ & $0.063^{*}$ & $0.003^{*}$ & 0.021 & 0.048 & $0.046^{*}$ \\
& $(0.035)$ & $(0.035)$ & $(0.002)$ & $(0.034)$ & $(0.031)$ & $(0.025)$ \\
Baseline share owning hyg. lat. & $0.212^{* * *}$ & $0.213^{* * *}$ & -0.003 & $0.088^{* *}$ & $0.192^{* * *}$ & $0.158^{* * *}$ \\
& $(0.044)$ & $(0.044)$ & $(0.002)$ & $(0.035)$ & $(0.044)$ & $(0.030)$ \\
Share of households landless & 0.026 & 0.027 & -0.002 & 0.018 & $0.046^{*}$ & 0.029 \\
& $(0.033)$ & $(0.033)$ & $(0.002)$ & $(0.030)$ & $(0.026)$ & $(0.026)$ \\
Union FEs & Yes & Yes & Yes & Yes & Yes & Yes \\
\hline Number of households & 14,116 & 14,055 & 14,055 & 14,098 & 14,098 & 14,103 \\
Number of groups & 980 & 980 & 980 & 980 & 980 & 980 \\
Number of villages & 84 & 84 & 84 & 84 & 84 & 84 \\
Omitted category mean & 0.258 & 0.259 & 0.001 & 0.187 & 0.183 & 0.153 \\
\hline
\end{tabular}

Notes: this table shows estimated treatment effects on indicators of indicators for different types of assistance (noted in the column header) the household reports receiving from others in the group. in the short term (at the time of assessment). The sample excludes pure control villages, so the omitted category consists of households in groups that received the basic health messaging treatment. Standard errors clustered at the village level in parentheses. ${ }^{*} p<0.10,{ }^{* *} p<0.05,{ }^{* * *} p<0.01$. 
Figure 1: Timeline for a typical village

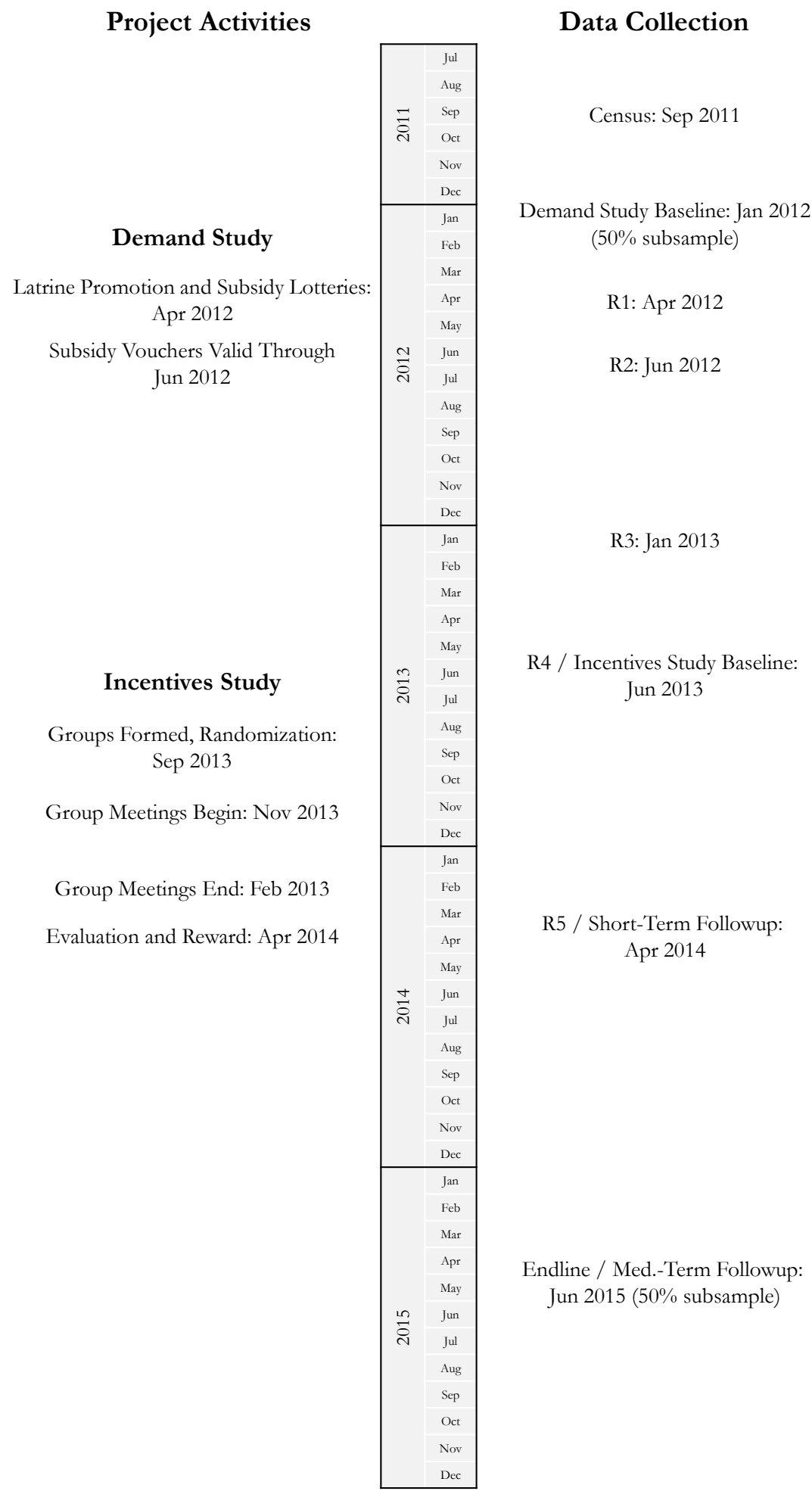


Figure 2: Short-term Effects: Hygienic Latrine Ownership

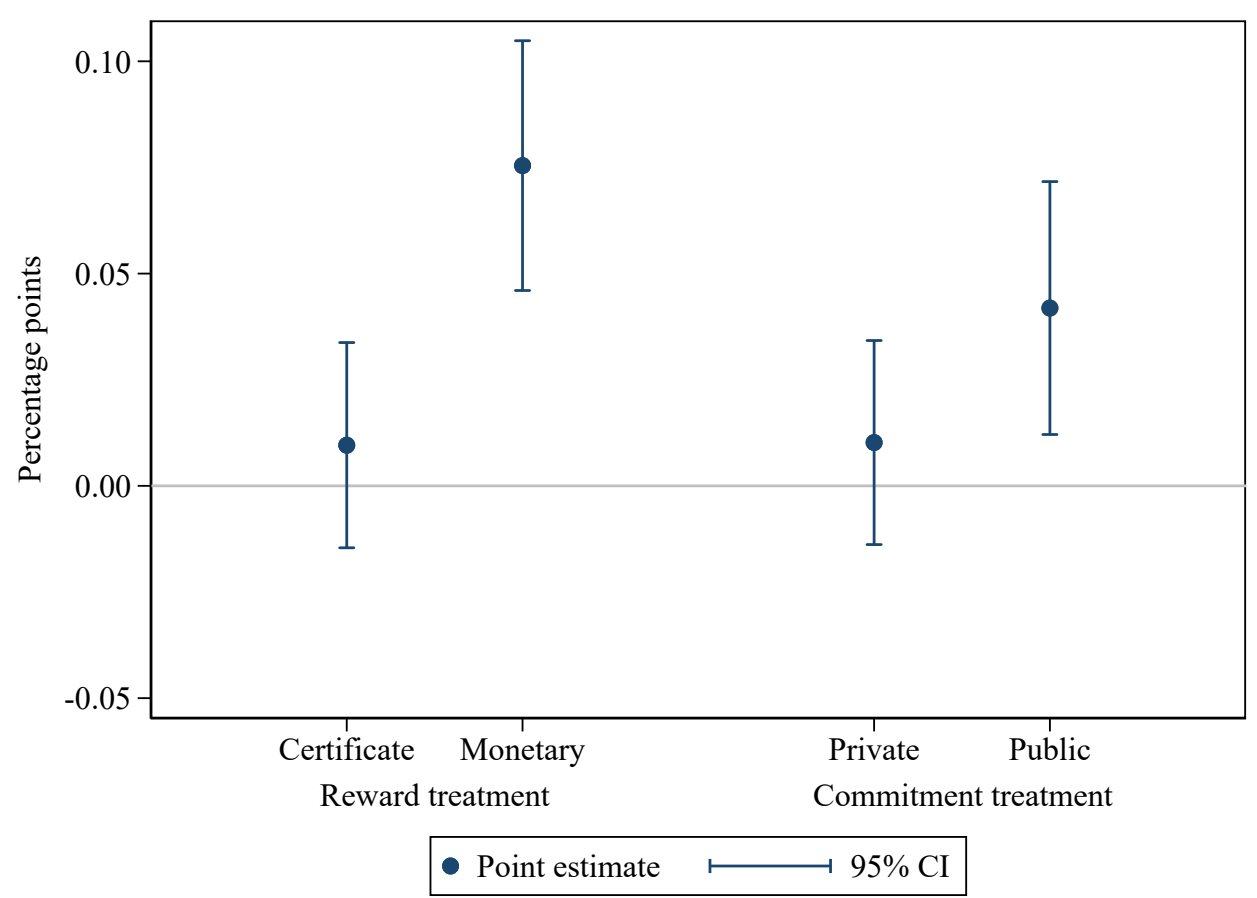

Notes: this graph presents estimated treatment effects of the interventions on the share of households in the group with a hygienic latrine in the short term (at the time of assessment). The regression includes for the baseline level of the outcome variable, the share of households in the group that are landless, and union fixed effects. Observations (groups) are weighted by the number of households. The sample excludes pure control villages, so the omitted category consists of groups that received basic health message on hygienic latrines and sanitation practices. $95 \%$ confidence intervals use standard errors clustered at the village level (the level of randomization). 
Figure 3: Medium-term Effects: Hygienic Latrine Ownership

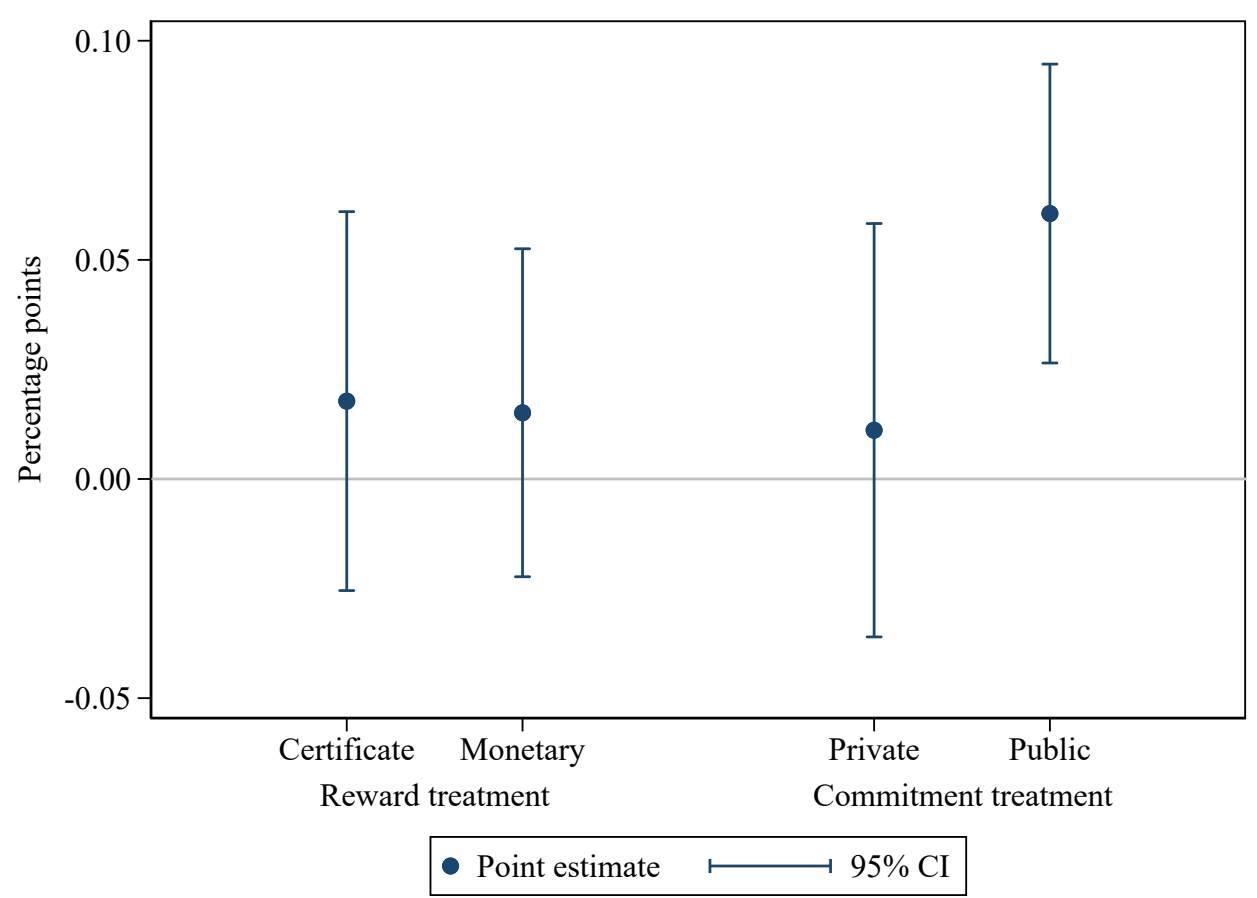

Notes: this graph presents estimated treatment effects of the interventions on the share of households in the group with a hygienic latrine in the medium term (12-15 months after assessment). The regression includes for the baseline level of the outcome variable, the share of households in the group that are landless, and union fixed effects. Observations (groups) are weighted by the number of households. The sample excludes pure control villages, so the omitted category consists of groups that received basic health message on hygienic latrines and sanitation practices. $95 \%$ confidence intervals use standard errors clustered at the village level (the level of randomization). 
Figure 4: Effect on Hygienic Latrine Ownership

By Household's Landless Status

(a) Short-term

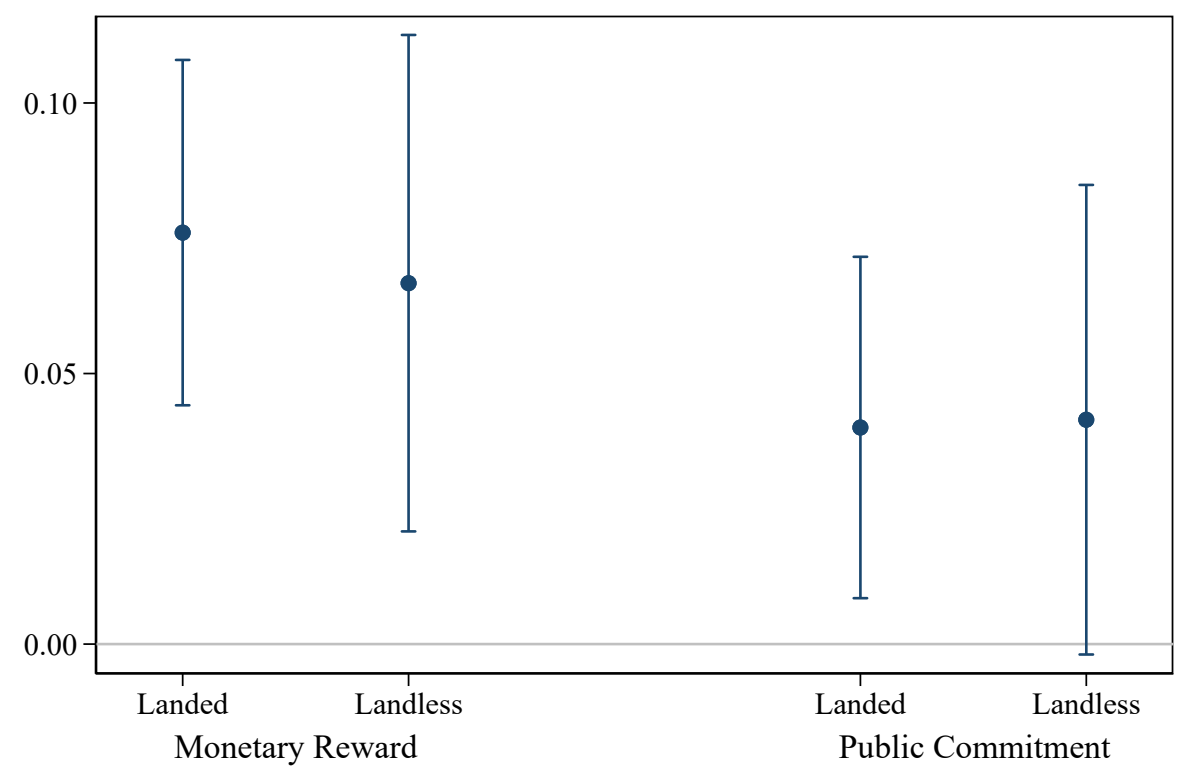

- Point estimate $\longmapsto 95 \% \mathrm{CI}$

(b) Medium-term

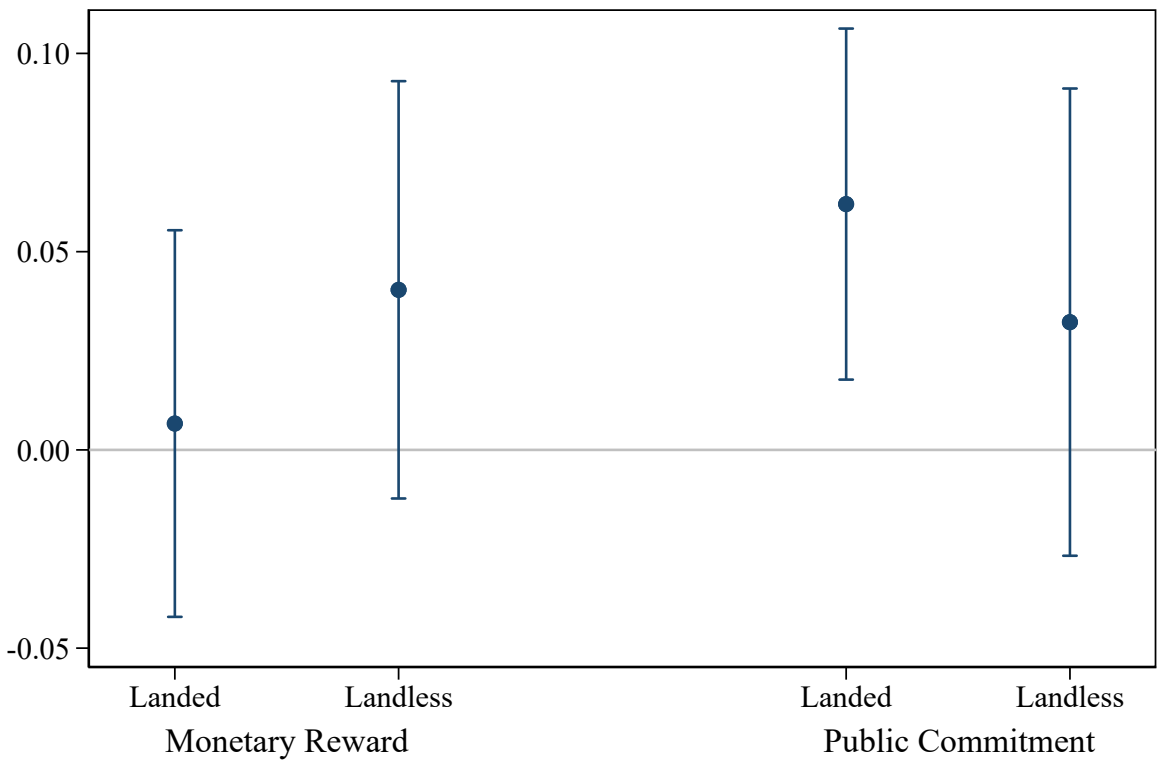

- Point estimate $\longmapsto 95 \%$ CI

Notes: these graphs present estimated treatment effects of the Monetary Reward and Public Commitment treatments on ownership of a hygienic latrine by household land ownership status. The top panel shows short-term effects and the bottom panel shows medium-term effects. The comparison group consists of households in villages receiving only the basic health intervention. The regression controls for group-level baseline hygienic latrine ownership, group share of landless households, and union fixed effects. $95 \%$ confidence intervals use standard errors clustered at the village level (the level of randomization). 
Figure 5: Effect on Hygienic Latrine Ownership

By Household's Baseline Latrine Ownership Category

(a) Short-term

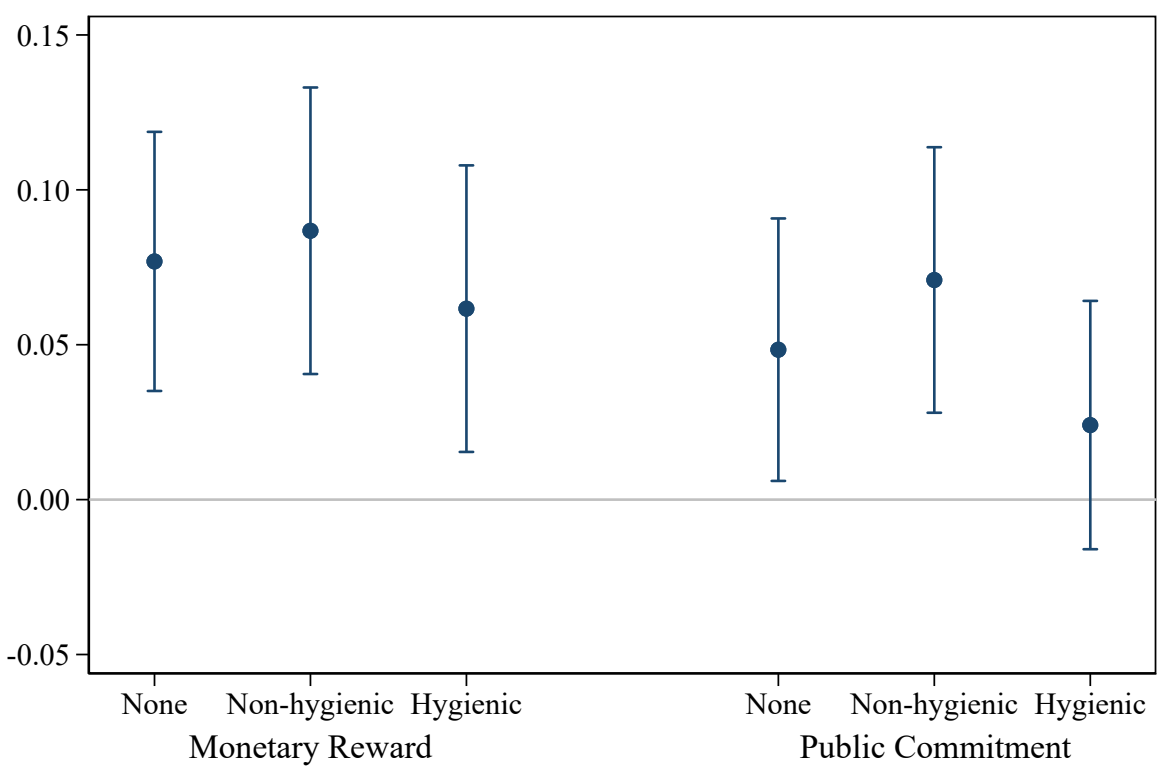

- Point estimate $\longmapsto 95 \%$ CI

(b) Medium-term

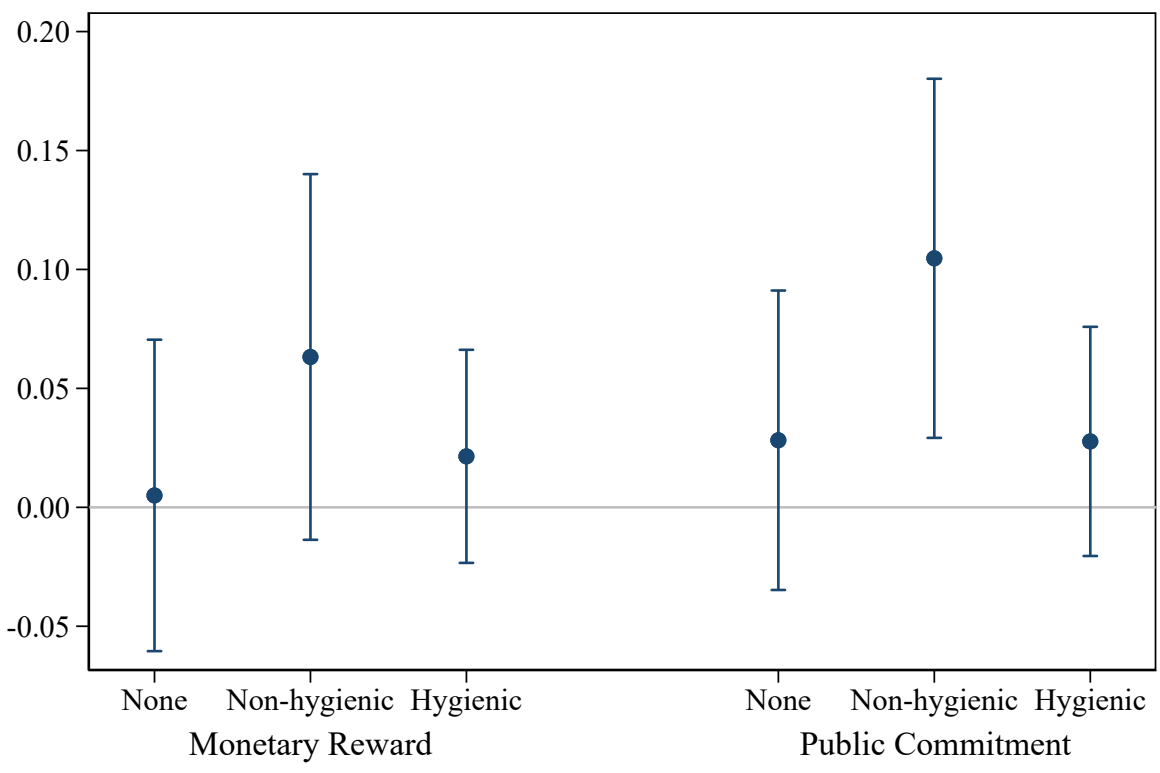

- Point estimate $\longmapsto 95 \%$ CI

Notes: these graphs present estimated treatment effects of the Monetary Reward and Public Commitment treatments on ownership of a hygienic latrine by category of baseline latrine ownership. The top panel shows short-term effects and the bottom panel shows medium-term effects. The comparison group consists of households in villages receiving only the basic health intervention. The regression controls for group-level baseline hygienic latrine ownership, group share of landless households, and union fixed effects. 95\% confidence intervals use standard errors clustered at the village level (the level of randomization). 